\begin{tabular}{|c|c|c|c|c|c|}
\hline MUNIBE Antropologia-Arkeologia & $n^{\circ} 65$ & $177-195$ & DONOSTIA & 2014 & ISSN $1132-2217 \bullet$ elSSN $2172-4555$ \\
\hline
\end{tabular}

\title{
La sauna de la Segunda Edad del Hierro del oppidum de Monte Ornedo (Cantabria, España)
}

\author{
The sauna of the Second Iron Age \\ of the Monte Ornedo hillfort (Cantabria, Spain)
}

KEY WORDS: Sauna, Iron Age, Cantabros.

PALABRAS CLAVES: Sauna, Edad del Hierro, Cántabros.

GAKO-HITZAK: Sauna, Burdin Aroa, kantabriarrak.

\author{
Pedro Ángel FERNÁNDEZ VEGA(1), Lino MANTECÓN CALLEJO(2), \\ Joaquín CALLEJO GÓMEZ ${ }^{(3)}$ y Rafael BOLADO DEL CASTILLO(4)
}

\begin{abstract}
In this paper we present the results of the excavation of a pre-Roman civil structure at the hillfort of Monte Ornedo (Cantabria, Spain). Its morphology, compartmentalisation and, above all, its functionality relate it directly with the saunas of the Hispanic Northwest, from Portugal to Asturias, or with the Irish fulachta fiadh and Atlantic burnt mounds. It is the first sauna documented in ancient Cantabria. Here we present its interpretive structural study and describe the materials found. With these and the radiocarbon determination, we can date this building in the late Iron Age, between the 2nd century BC and the Cantabrian Wars (29-19 BC).
\end{abstract}

\section{RESUMEN}

En el presente artículo se presenta los resultados de la excavación del Sondeo 3 del yacimiento prerromano de Monte Ornedo (Valdeolea, Cantabria), una estructura cuya compartimentación y funcionalidad parecen relacionarla con una sauna.

\section{LABURPENA}

Artikulu honetan ageri dira Ornedo mendiko (Valdeolea, Kantabria) aztarnategi prerromatarreko 3. zundaketako indusketaren emaitzak. Haren egituraren funtzionaltasuna eta konpartimentazioa ikusita, sauna batekin erlaziona dezakegu.

\section{1.- INTRODUCCIÓN}

Las distintas campañas realizadas desde 1906 en el Monte Ornedo (SCHULTEN, 1942; BOHIGAS, 1978; FERNÁNDEZ y BOLADO DEL CASTILLO 2010), y especialmente las desarrolladas desde el año 2003, con el apoyo de la Consejería de Educación, Cultura y Deporte del Gobierno de Cantabria, el Servicio Cántabro de Empleo y el Ayuntamiento de Valdeolea, han puesto al descubierto al primer oppidum de la Cantabria actual (Figura 1). Al margen de su sistema defensivo compuesto por dos líneas de muralla de doble paramento y, al menos, una puerta en esviaje, su singular importancia radica en la conservación de un edificio público de gran tamaño. La excavación, compartimentación y estudio de las estancias nos permite identificarlo con un edificio del tipo sauna que puede relacionarse con el con- junto de saunas halladas en el Noroeste hispánico desde Portugal a Asturias o, morfológica y funcionalmente, con los fulachta fiadh irlandeses y con las burnt mounds atlánticas.

Gracias a este trabajo no sólo podemos incorporar al catálogo un nuevo ejemplar, inmerso en una construcción pública de inusitado tamaño y desacostumbrada complejidad constructiva, sino que a su vez se pone en evidencia la existencia de vínculos, tradiciones o costumbres comunes que, con sus particularidades, pueden rastrearse por todo la Europa atlántica.

Para una mejor compresión el artículo se ha dividido en dos grandes bloques: un primero dedicado a la descripción de la estructura, ambientes y hallazgos arqueológicos, un segundo centrado en la interpretación y contextualización del edificio.

\footnotetext{
(1) Consejería de Educación, Cultura y Deporte del Gobierno de Cantabria.

(2) Arqueólogo profesional.

(3) Arqueólogo profesional

(4) Doctorando de la UC-IIIPC/Proyecto arqueológico Cueva del Aspio.
} 


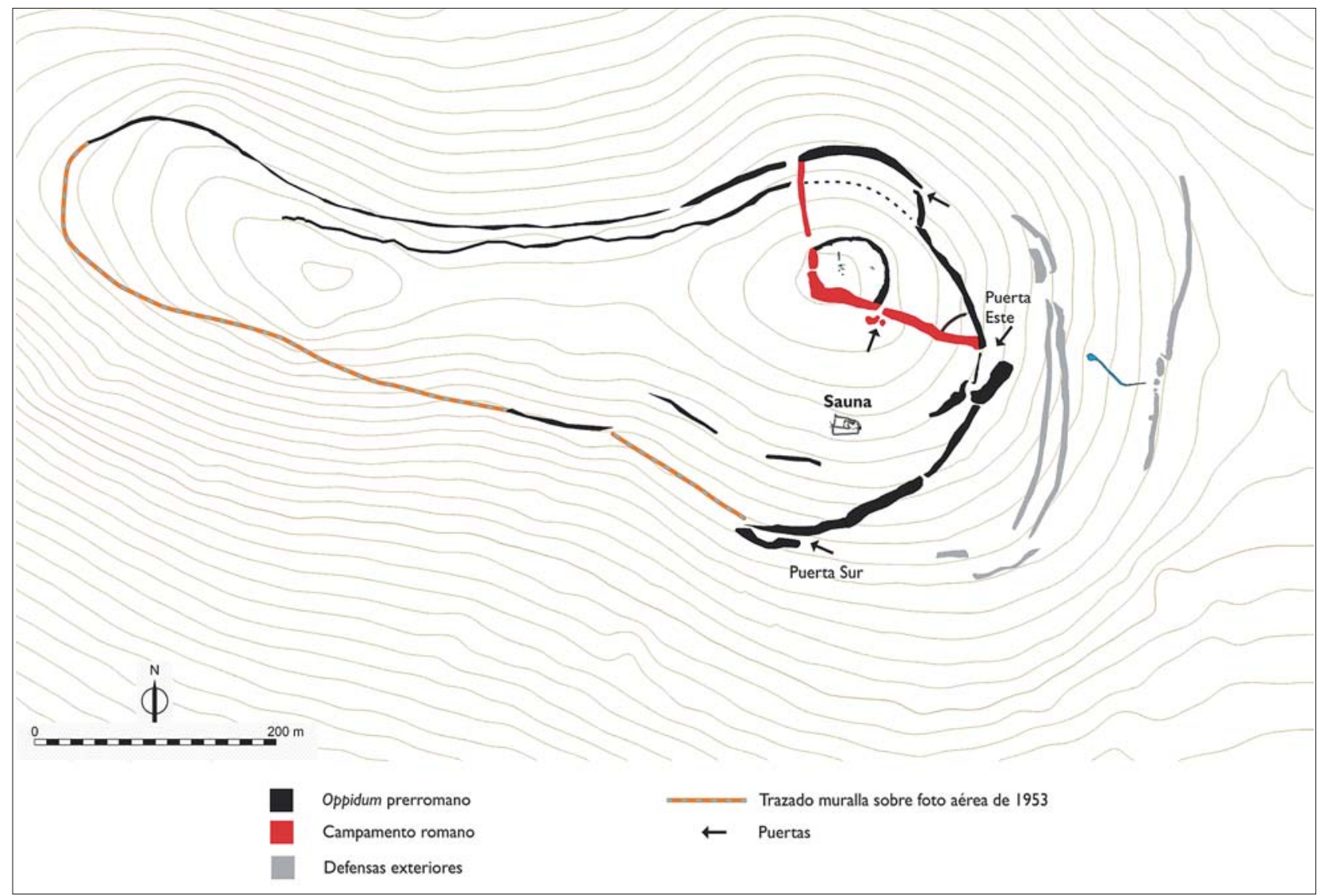

Fig. 1. Croquis del yacimiento de Monter Ornedo. / Sketch of the Monte Ornedo's hillfort.

\section{2.- LA SAUNA}

La estructura, de planta trapezoidal, fue construida intramuros en la vertiente sur del enclave, aprovechando y adaptándose a un aterrazamiento natural, lo que obligo a dividirla en dos partes: un recinto inferior al sur, y otro, de mayor tamaño, al norte.

El edificio tiene unas dimensiones de 24,25 m de largo por 16,30 m de ancho en la zona oeste y 10,30 m en el extremo este, ocupando un área de 303,74 $\mathrm{m}^{2}$ con las estructuras anexas. En la terraza septentrional se han distinguido dos zonas: una al oeste que alberga una gran sala con pasillo (ámbito 1) y un patio central abierto (ámbito 2) con cisterna en su lateral para la recogida de aguas (ámbito 3), y otra al este dotada de sala y una sauna de arcilla (ámbitos 4 y 5). La terraza sur no ha sido excavada en su totalidad (ámbito 9). Al exterior la estructura cuenta con un pasillo o rampa de acceso (ámbito 8), una pequeña estructura anexa al este (ámbito 6) y un área de cenizal (ámbito 7) (Figura 2 y 3 ).

La construcción de los muros de carga se ha realizado mediante muros de mampostería con cara vista externa, mientras que el interior se realiza en tierra compactada con abundante cascajo y piedra suelta. Por zonas se elevarían lienzos murarios de manteado sobre zarzo o tapiales de tierra y cascajo de piedra. El ancho de los muros oscila entre los $95 \mathrm{~cm}$ y los $105 \mathrm{~cm}$.

Se ha constatado el uso de enlucidos de manteado de barro que aparecen sueltos por el suelo de las estancias. Ninguno de los fragmentos conserva huellas de entramados vegetales por lo que es posible que recubrieran muros de mampostería, tablazones de madera o tapiales. El grado de endurecimiento de los fragmentos conservados, así como su asociación a piedras con claras evidencias de haber sufrido el efecto del fuego, nos permiten afirmar que el edificio se incendió (Figura 4).

El suelo está representado por un sencillo nivel de tierra apisonada. La cubrición de la estructura, ante la ausencia de tejas, nos hace pensar en una techumbre orgánica cuyos pies derechos se asentaron sobre varias rocas de gran tamaño dispuestas sobre la roca madre.

El edificio conserva dos accesos. Uno en el lado oeste con puerta de madera y herrajes de hierro y otro estrecho en el lado este.

\subsection{La gran sala (ámbito 1)}

Localizada en el extremo noroeste del edificio presenta una superficie útil de $61,10 \mathrm{~m}^{2}$ y una puerta de entrada 


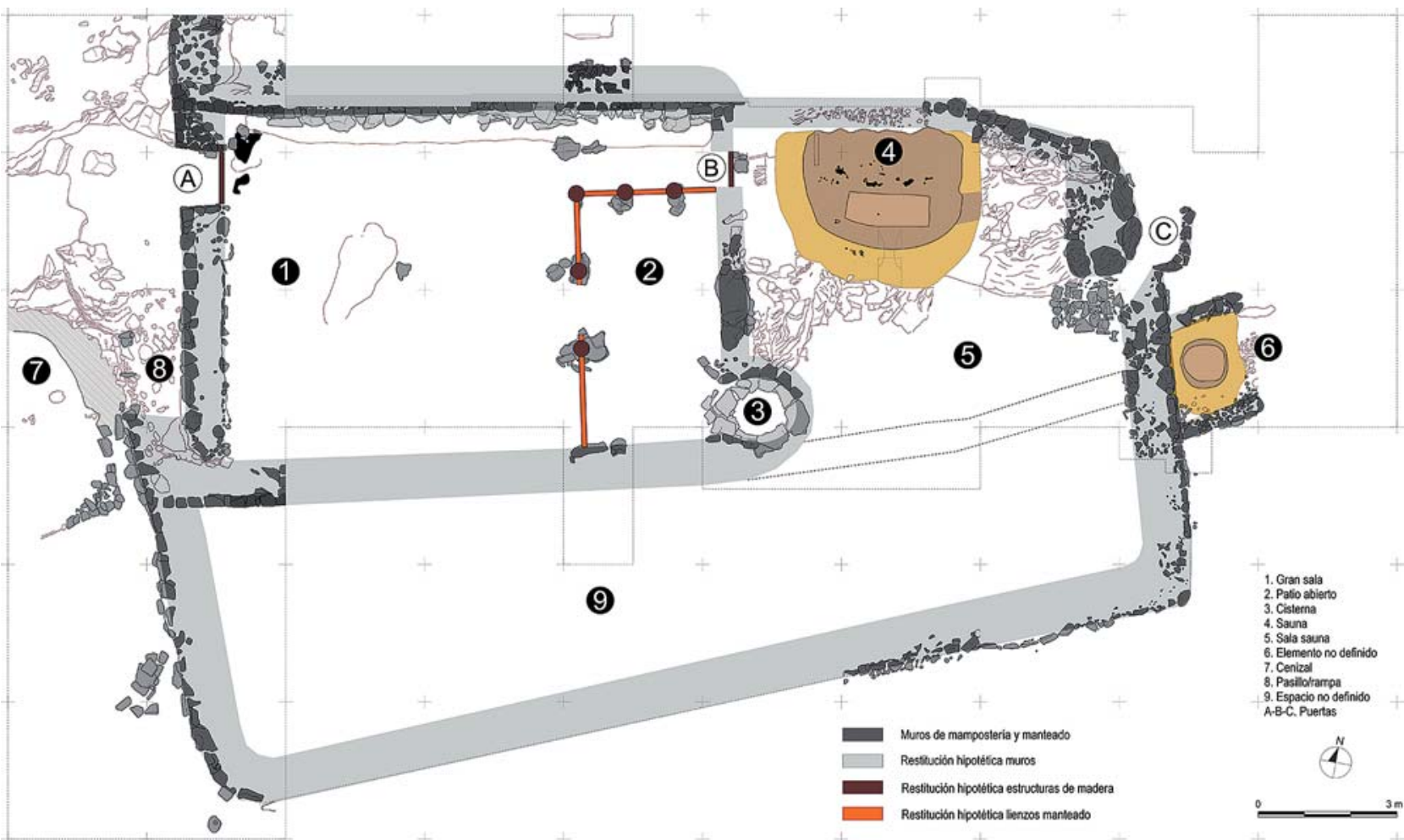

Fig. 2. Plano de la sauna. / Plane of the sauna.

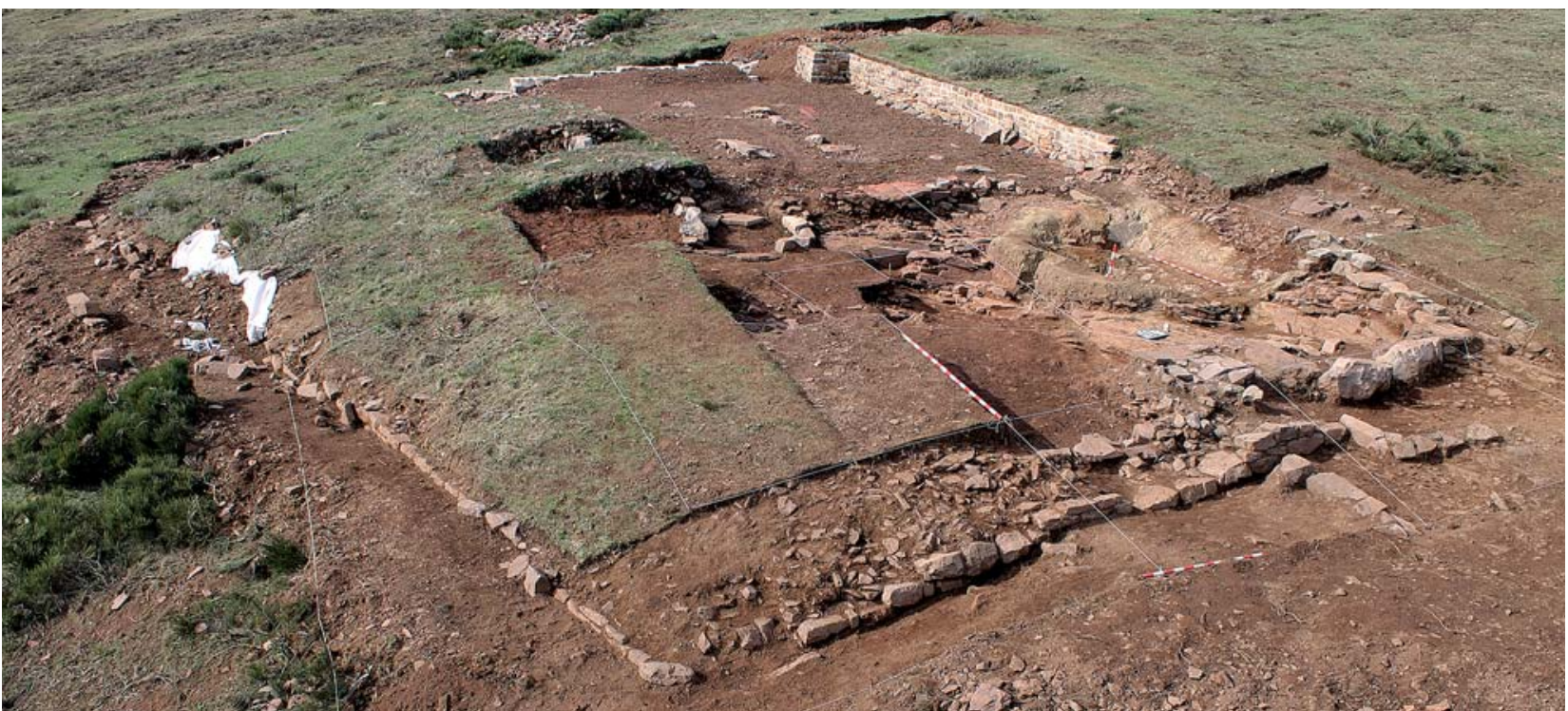

Fig. 3. Sauna.

desde el exterior (Figura 2). Los muros norte, oeste y sur son muros de piedra de carga, los dos primeros exteriores y el meridional para soportar el peso de la techumbre.

El muro norte se construye como lienzo mataterrero. Tiene una longitud de 10,30 m y está realizado con mampuestos regularizados, sin argamasa y con cimentación de grandes bloques informes de arenisca asentados sobre la roca madre. De sus extremos nacen los lienzos este y oeste en posición perpendicular. En la esquina oeste se adosa un muro, a modo de contrafuerte, que se aprovecha para abrir la puerta. En el caso de la esquina este solo se observa el encastre de ambos imbricados en una hilada. En los extremos se abrirían sendas puertas enfrentadas, la oeste para dar acceso al edificio y la este para dar acceso a la sauna.

El muro de carga oeste está construido con técnica mixta, una cara o lienzo exterior de mampuesto sin arga- 


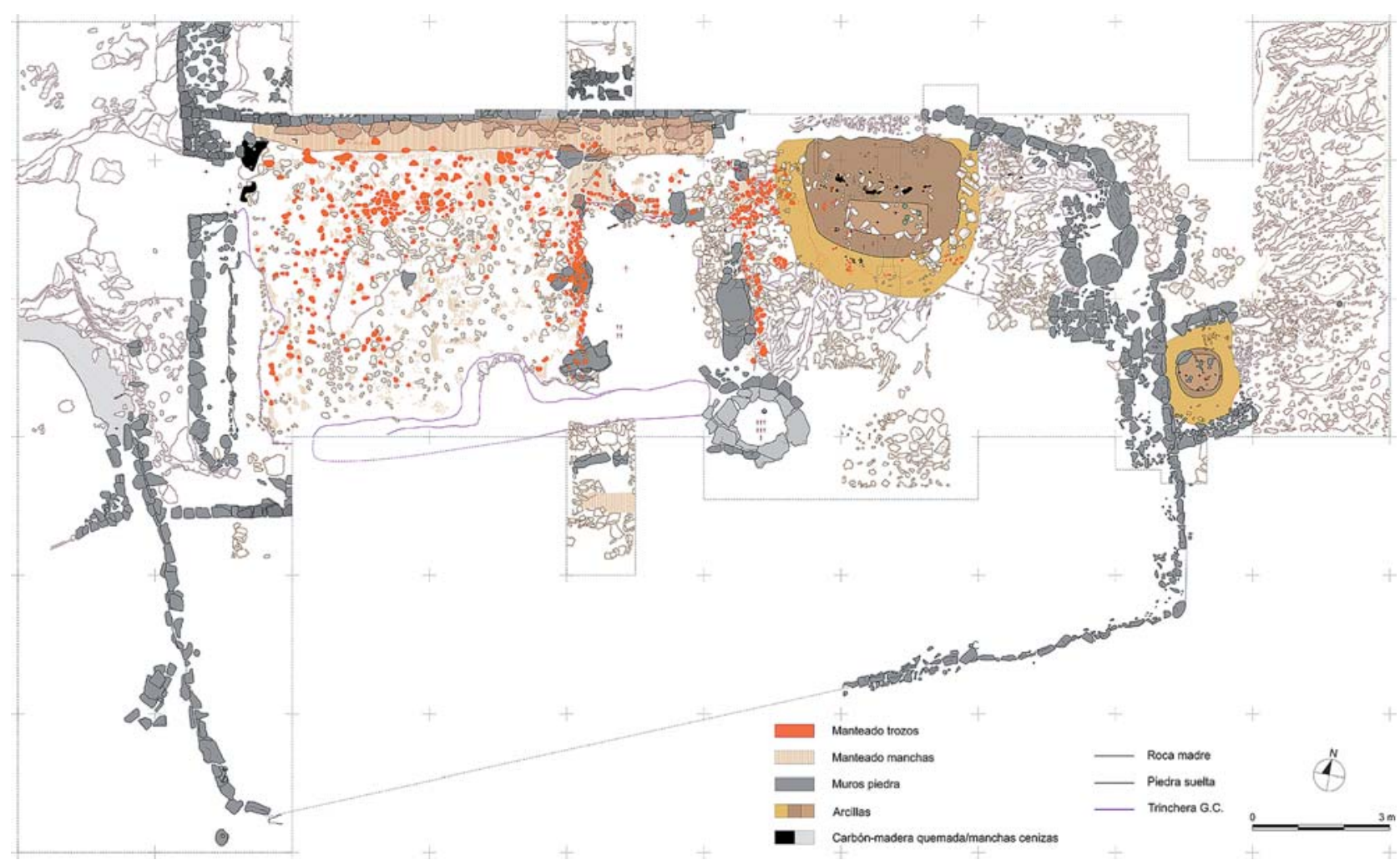

Fig. 4. Plano de la sauna con dispersión de los restos de manteado de barro / Plane of the sauna with remains of mud of walls.

masa y el interior de tierra compactada. Conserva una anchura de entre $80-90 \mathrm{~cm}$ y una longitud de $5,7 \mathrm{~m}$.

El muro sur se fabrica de forma similar al norte. La zona interior conforma una sala diáfana apoyada en un pie derecho central. Al nordeste, entre la estructura del patio (ámbito 2) y el muro norte se sitúa un corto pasillo de 3,30 x 1,78 m.

La puerta noroeste es la mejor conservada del edificio. Se trata de un vano de 1,3 a 1,15 m de anchura abierto en el contacto del muro oeste de la estancia con el muro norte de la estructura. Se ha elaborado añadiendo en ángulo recto un muro adosado al lienzo norte de $80 \mathrm{~cm}$ largo y 1,3 $\mathrm{m}$ de ancho continuando la misma factura muraria. Junto a la puerta se localizó una clavija de bisagra o pernio de hierro en "L", de sección cuadrangular, remate cónico y restos de pintura roja (Figura 5). En la base de la puerta, bajo el derrumbe de manteado, un tablón carbonizado, probablemente fruto del incendio del edificio, nos proporcionó una fecha de 2120ะ30 BP (Poz-45374), entre el siglo II a.C. y la primera mitad del I a.C. Este análisis corrobora la datación efectuada en este mismo lugar en la campaña de 2010, sobre el nivel de manteado en la parte alta del derrumbe, cuyo resultado, 2095 \pm 35 BP (Poz-38821), nos emplaza en el mismo arco cronológico.

El registro material recuperado es bastante escaso: herrajes, clavos, un objeto indeterminado de bronce y varios fragmentos cerámicos entre los que destaca un fondo oxidante a torno umbilicado (Figura 6, 2).
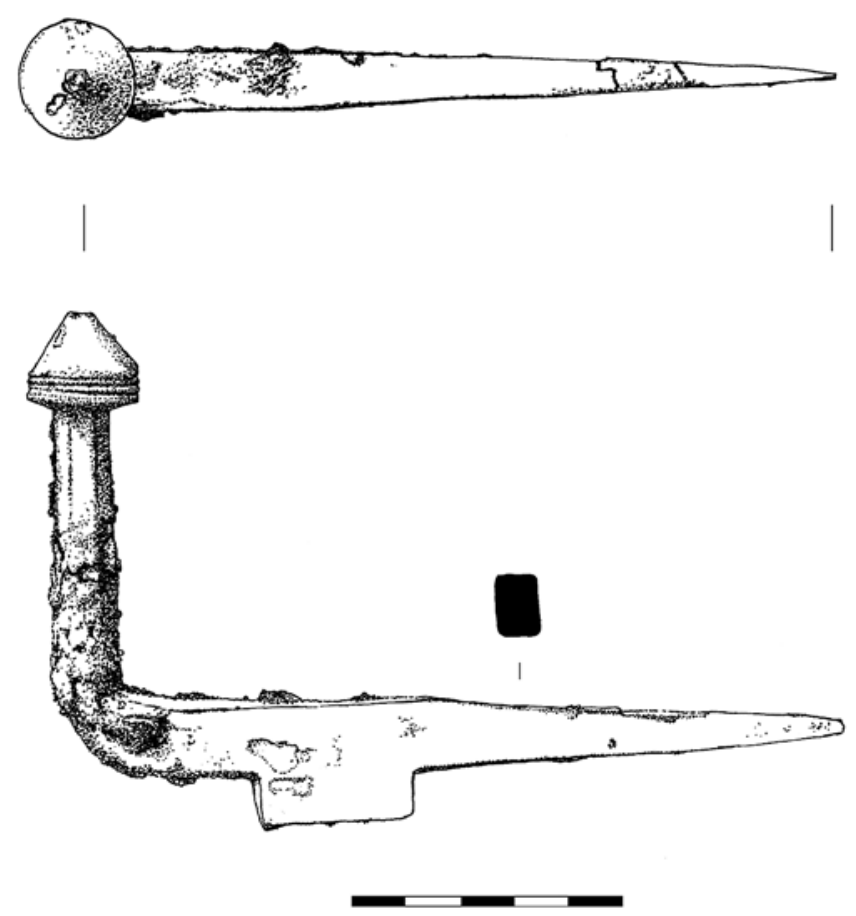

Fig. 5. Pernio / Hinge 

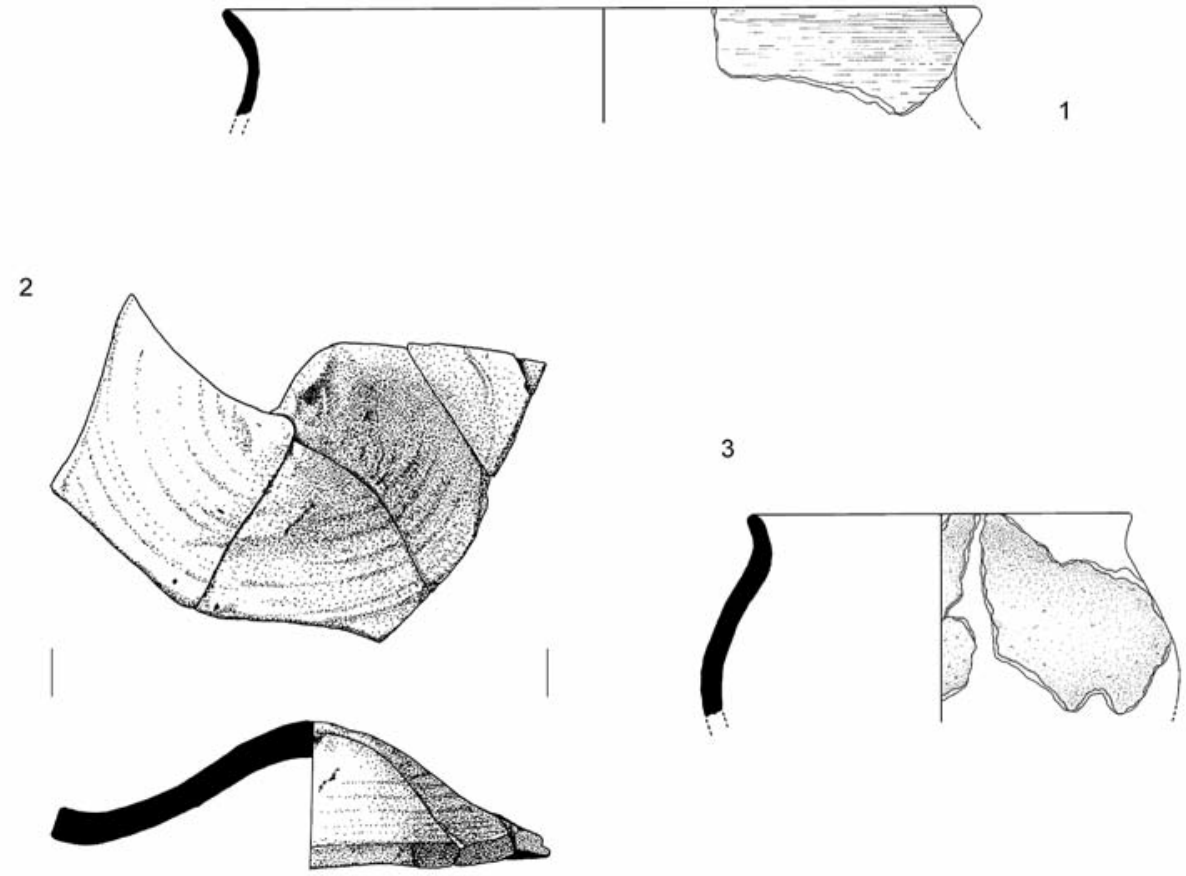

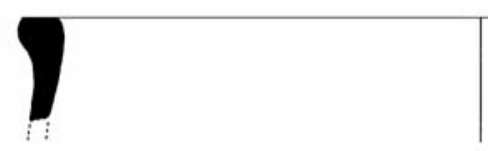

\subsection{El patio abierto (ámbito 2)}

En la esquina sureste del ámbito 1, se abre un patio abierto rectangular de unos 5,5 × $3 \mathrm{~m}$, que ocupa una superficie de $17,22 \mathrm{~m}^{2}$, en la que se recogerían las aguas para almacenarlas en una cisterna perforada ubicada en la esquina sureste. (Figura 2, ámbito 3).

El patio estaba rodeado de pilares o pies derechos de madera de los cuales no se ha conservado más evidencia que cinco cimentaciones de piedra arenisca. Estas se distribuyen por los lados norte y oeste del patio, estando el lado este formado por un muro. El lado sur se halla alterado por una trinchera de la Guerra Civil.

El espacio entre los pilares en su lado oeste y norte debió estar cerrado con un lienzo de tablazón o entramado vegetal recubierto de barro. Los restos de estos muros aparecen en forma de bandas de manteado a lo largo de los bordes del patio asociados a algunos clavos de hierro de gran tamaño y sin apenas piedra.

El interior se encuentra a un nivel más bajo que el resto de las estancias situadas al este y oeste, quizás para ofrecer una zona de decantación de aguas y evitar el drenaje de las mismas hacia otro lugar que no fuera la cisterna. El suelo del patio aparecía como tierra o roca madre con un

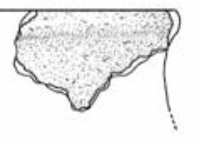

4
Fig. 6. Restos cerámicos: 1-2) cerámica a torno, 3-4) cerámica a mano / Pottery: 1-2) pottery by lathe, $3-4$ ) pottery by hand. pequeño desnivel del $5 \%$ a favor de la cisterna. En este nivel fue recuperado un escoplo de hierro con enmangue de hueso o asta similar al ejemplar de Retortillo (Campoo de Enmedio, Cantabria) (IGLESIAS, 2002: 173-175) o los de la Cueva de Reyes (Matienzo) (SMITH, 1996). Posee una longitud de 20,2 cm, una sección rectangular de 14,8 x $18 \mathrm{~mm}$ con filo a bisel de $29 \mathrm{~mm}$ y un pequeño saliente rectangular a mitad de la hoja de 13,7 x 0,75 ×0,75 mm. Muestra un enmangue en espiga de $7,5 \mathrm{~cm}$ complementado por un aro de sujeción de 46,3 mm de diámetro y 4 $\mathrm{mm}$ de grosor, en el cual se aprecian restos del mango de asta o hueso. En el borde del patio se recuperaron también dos asas con sus alcayatas pertenecientes a un caldero de madera y un par de clavos en $L$ que mostrarían un grosor de las paredes de unos $3 \mathrm{~cm}$ (Figura 7).

Nuevamente hay que destacar el hallazgo de varios clavos y láminas de hierro asociados al derrumbe de manteado que pueden relacionarse con la clavazón para la carpintería de armar y/o las separaciones de tablazón. Cerca de éstos, entre la capa de manteado, se halló una clavija de bisagra de hierro con pintura roja, de 7,4 cm de longitud. Estas evidencias, asociadas a cuatro fragmentos de láminas de hierro, parecen indicar que el acceso al patio abierto desde la gran sala (ámbito 1) se efectuaba entre pilar y pilar, por el centro del lado oeste del patio. 


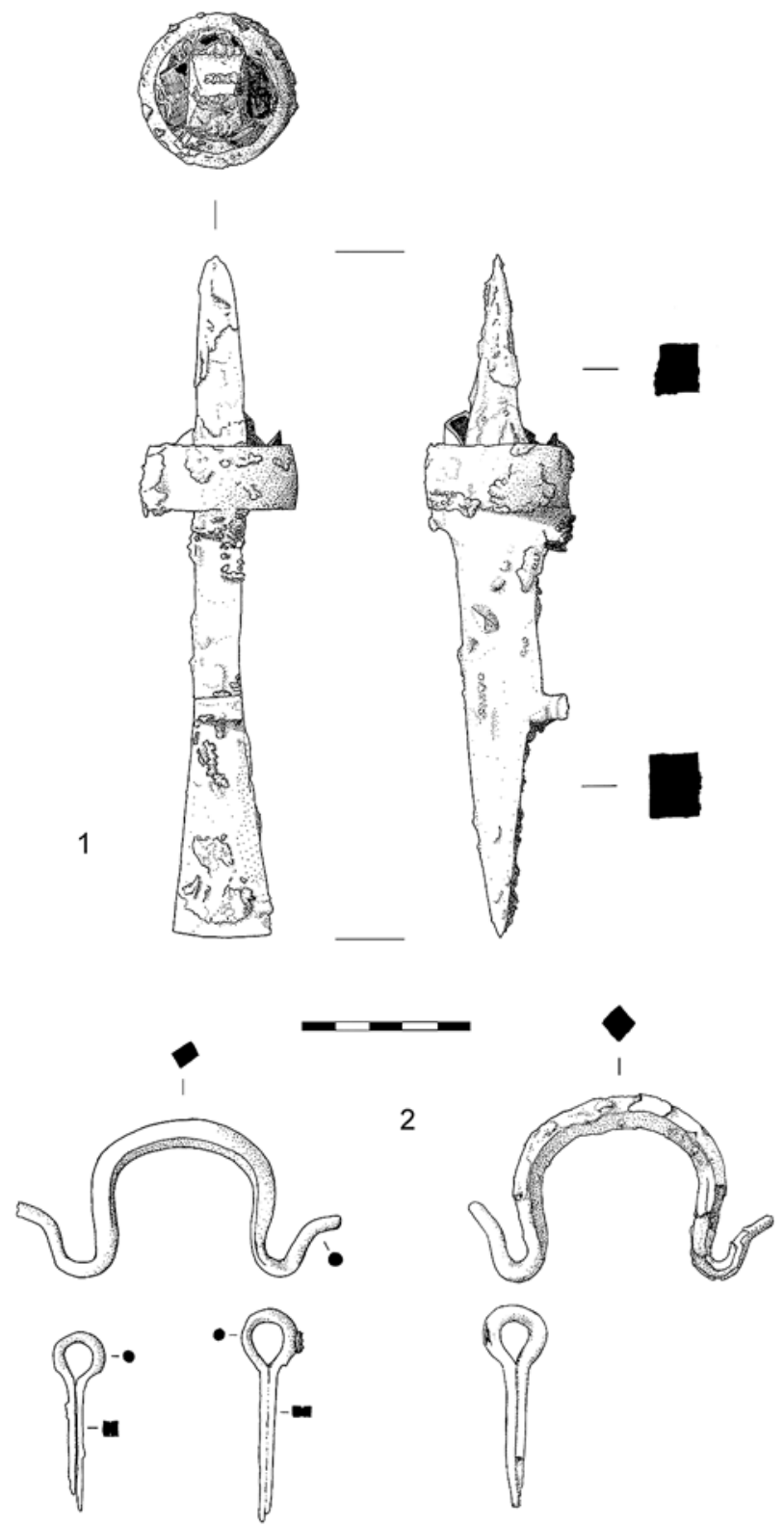

Fig. 7. Escoplo y piezas de caldero / Chisel and parts of cauldron.

\subsection{Cisterna (ámbito 3)}

En la esquina SE del patio fue localizada una cisterna con brocal circular e interior prismático que recogía las aguas del patio pero que físicamente se inscribía en el interior de la sala de la sauna (ámbito 5), desde la cual tendría un acceso. Su ubicación fuera del patio abierto tendría una doble funcionalidad: que el agua estuviera a cubierto y poder formar parte del sistema de baños de vapor (Figura 2 y 8 ).

La cisterna consta de un muro semicircular abierto en su extremo occidental hacia el patio. El muro se realiza con una cara de mampuestos labrados del que apenas se conservan dos hiladas, con unas dimensiones interiores de 1,48 $\mathrm{m}$ de diámetro que haría las veces de brocal. Este muro se

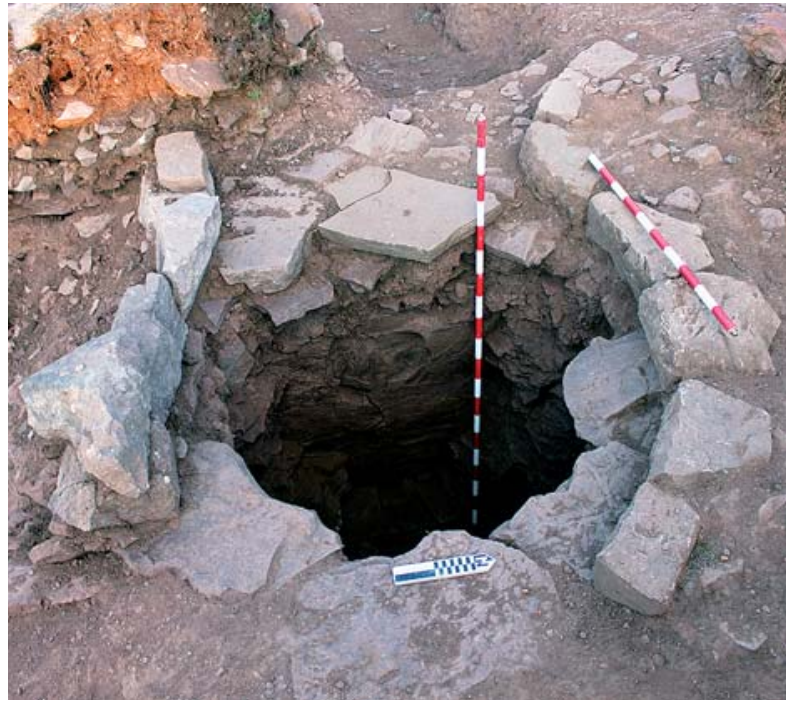

Fig. 8. Cisterna / Tank.

asienta sobre losas prismáticas de arenisca de entre 5 y 20 $\mathrm{cm}$ de espesor, colocadas en la misma disposición que el muro que sustenta y extendiéndose hacia el interior en voladizo formando una boca circular irregular más estrecha con una apertura de $1 \mathrm{~m}$ de diámetro. Las losas buzan levemente hacia el centro o interior como si conformaran una especie de vierteaguas para llenar la cisterna.

En su interior las paredes muestran una sección rectangular de $1,15 \mathrm{~m}$ y 1,45 $\mathrm{m}$ alcanzando una profundidad de $1,30 \mathrm{~m}$. El relleno estaba formado por un paquete compuesto, en su mayor parte, por piedras de derrumbe, una matriz de tierra arenosa y trozos de manteado. Las paredes internas del pozo estaban labradas en la roca madre, con cuatro paredes verticales escuadradas. La cavidad va ampliándose en anchura por debajo de las losas superiores que vuelan entre 10 y $40 \mathrm{~cm}$, proporcionándole una mayor anchura que la de la boca del mismo. Las losas en voladizo se sostienen al estar pinzadas bajo el muro semicircular de mampostería. Esta circunstancia obligaría a que la estructura interna del brocal estuviera sustentada por algún tipo de entramado de madera, de la que no se han hallado restos salvo algunos clavos de grandes dimensiones (Figura 9).

Del relleno interior del pozo se ha recuperado un "pendiente amorcillado" de bronce, diversos clavos, así como varias escorias, fragmentos de manteado y dos manos de molino de cuarcita.

\subsection{Sauna (ámbito 4)}

Se localiza dentro del ámbito 5 (sala de la sauna), levemente descentrada hacia el oeste sobre la pared norte y parcialmente excavada en la roca arenisca de base hasta una profundidad media de 1,46 m. Sobre este hueco se colocó un gran depósito artificial de arcilla amarilla compactada de forma semicircular que alcanza $1,77 \mathrm{~m}$ de potencia. Posee los lados rectos, de 4,41 m x 3,44 m, 


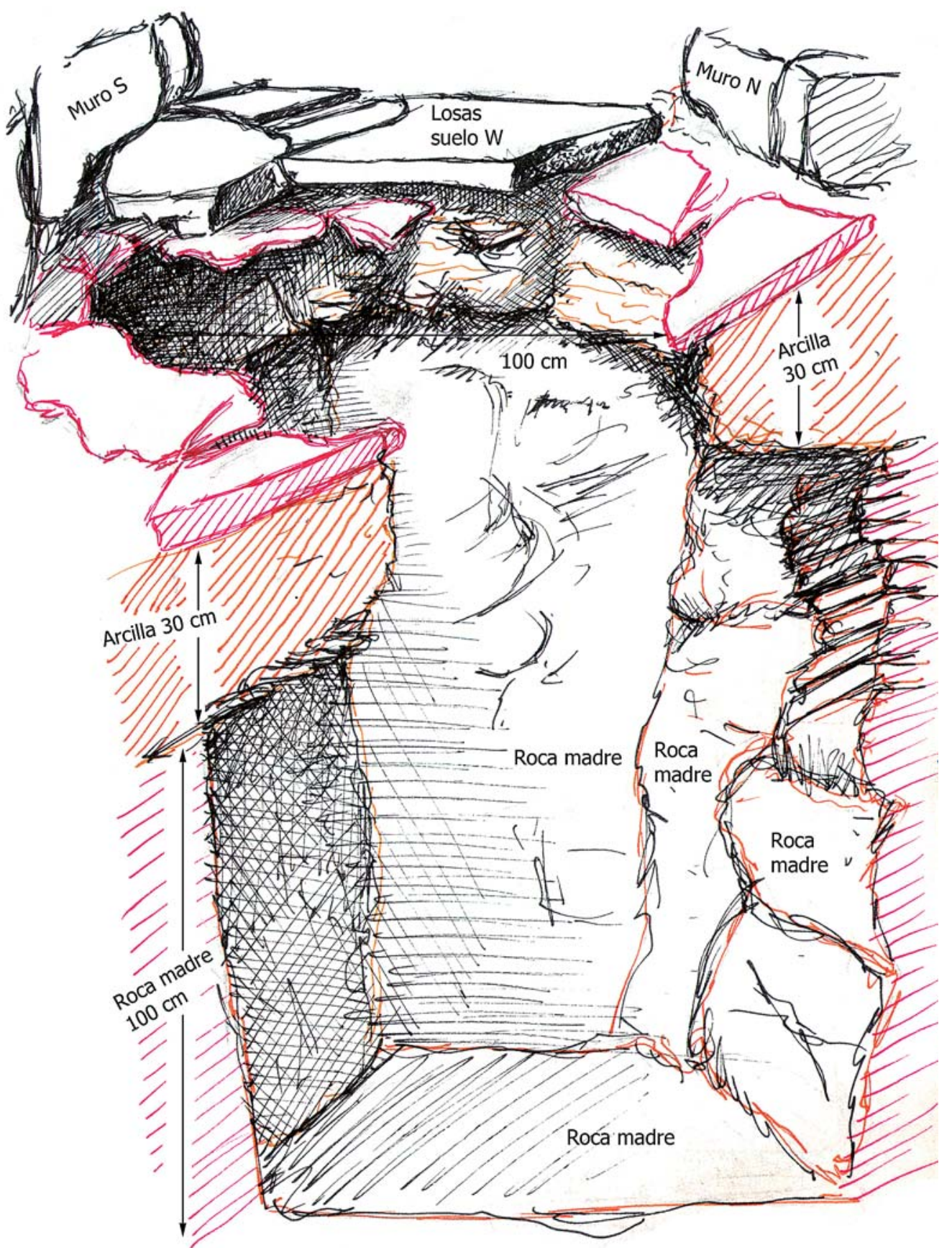

Fig. 9. Dibujo de la sección de la cisterna / Drawing of the section of the tank.

ocupando una superficie de $13,3 \mathrm{~m}^{2}$ de la cual 7,66 $\mathrm{m}^{2}$ serían útiles. En su centro se ha dejado un hoyo o vaso rectangular de 1,77 x 0,70 m y 1,19 m de profundidad. La arcilla funcionaría primero como aislante térmico, pero también como impermeabilizante de las aguas que se verterían durante el baño de vapor (Figura 2 y 10).

La sección N-S presenta una estructura singular en forma de embudo. El vaso de la sauna propiamente dicho tiene forma de matraz con el fondo levemente abierto hacia el exterior de 0,87 $\mathrm{m}$ ancho y las paredes rectas hasta la boca dejando un ancho menor de $70-78 \mathrm{~cm}$. El fondo o suelo está levemente redondeado. Desde el borde de la boca hasta la coronación de las arcillas las paredes están inclinadas. El grosor de las paredes de arcilla alcanza 1,25 m. En su interior, para aportar consistencia, se dispone un murete sencillo de piedra de cuatro hiladas en la cara sur, mientras el resto de los lados tiene como sustento el sustrato geológico de roca arenisca.

A unos $30 \mathrm{~cm}$ al norte del borde del vaso fueron localizados los restos de un madero dispuesto de oeste a este, 


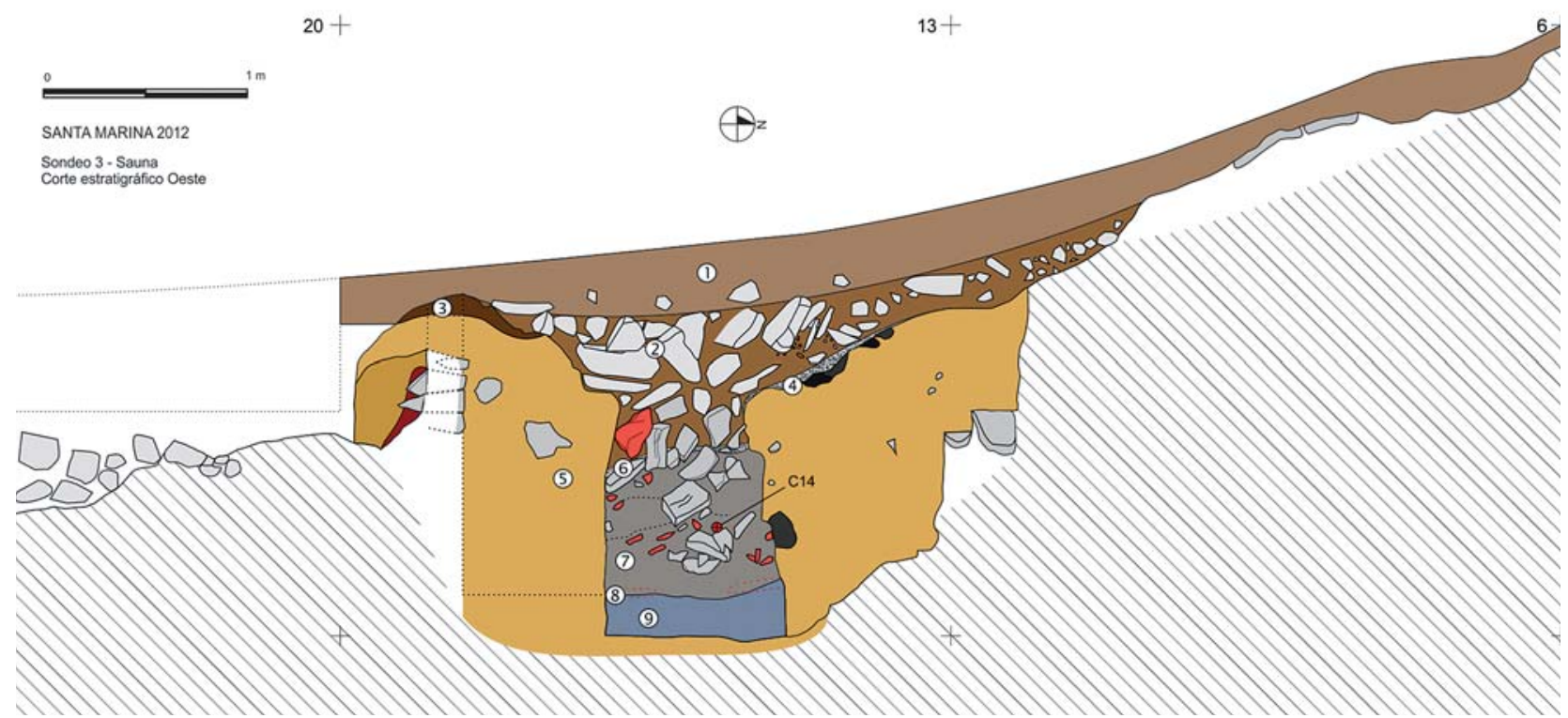

Fig. 10. Sección estratigráfica de la sauna. / Stratigraphic section of the sauna.

así como cinco clavos de $1 \mathrm{~cm}$ de grosor y cabeza circular clavados en la propia capa de arcilla de la pared sur y este, que indican que la sauna podría contar con un asiento de madera donde colocarse para recibir el baño de vapor. Este ocuparía una superficie aproximada de $3,53 \mathrm{~m}^{2}$.

Del interior del vaso fueron recuperados también cantos de arenisca fina o cuarcitas entre los que se han constatado algunas afiladeras y manos de molino fragmentadas. Los cantos están afectados por el calor, con manchas carbonosas adheridas que indica que fueron calentados y depositados en el fondo. Sobre ellos se vertería agua para generar vapor de agua e intensificar la sensación de calor.

Carbones, mezclados con piedras y arcillas cocidas, podían encontrarse también en el nivel 7 del derrumbe del vaso. Uno de ellos fue datado por C14-AMS (Poz-53223) en 2120 \pm 35 BP lo que nuevamente nos lleva a una avanzada Segunda Edad del Hierro, entre finales del siglo III a.C y el siglo I a.C.

Entre los materiales procedentes del relleno del vaso destacan dos galbos fabricados a mano y de cocción oxidante y cuatro fíbulas de aro sin resorte "omega". Corresponden con el tipo 35 de Erice (1995: 207-225) o a los tipos 21.2.b9 (Figura 11, 1), 21.2.b6 (Figura 11, 2) y 21.2.b8 (Figura 11,3 y 4), como variantes de los mismos, de Mariné (2001: 258-272). Todas ellas están alteradas por la acción del fuego y fueron halladas en la capa más profunda (nivel 9).

Como es sabido, este tipo de fíbulas no permiten por el momento y por sí mismas realizar precisiones cronológicas. No obstante se enmarcan a la perfección entre los siglos II-I a.C que proporcionan las dataciones absolutas (ERICE, 1995: 213-215; MARINÉ, 2001: 268-272).
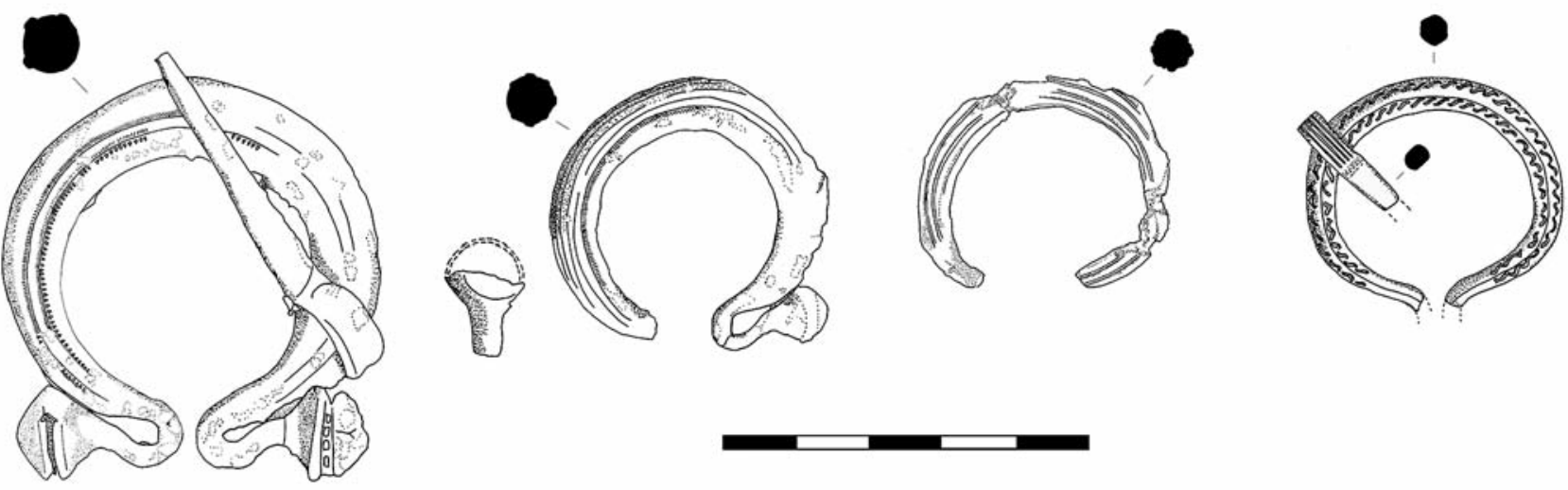

Fig. 11. Fíbulas anulares / Annular fibulas. 


\subsection{Sala de la sauna (ámbito 5)}

La sauna se inserta dentro de una sala mayor localizada en el extremo este del edificio. Esta ocupa un área aproximada de $44,41 \mathrm{~m}^{2}$ y posee unas dimensiones de $6,27 \mathrm{~m} \times 8,05 \mathrm{~m}$ de E-W. Parece que el edificio, en la terraza superior, se remata al este con una cabecera trapezoidal (Figura 2).

De los muros atestiguados, el norte, de 8,25 m de longitud, no sigue la misma dirección que el documentado en la gran sala (ámbito 1) sino que comienza a cerrarse levemente hacia el sur. El muro este, de 10,30x1,05/1,10 m tiene varias particularidades. En su extremo norte se engrosa hasta alcanzar los 1,60 m rematándose con grandes bloques de arenisca a lo largo de 2,96 m. Al final de este grueso muro se abre una puerta estrecha de apenas 50 a $85 \mathrm{~cm}$ de ancho, rematada al exterior por un murete o parapeto de piedra, de una hilada de apenas $25 \mathrm{~cm}$ de ancho y una única cara en forma de arco o clavícula. Tras pasar al interior se desarrolla un rústico enlosado de lajas de arenisca ocupando una superficie de 1,25 x 1,30 m.

El muro oeste de esta sala limita con el muro medianero de la gran sala (ámbito 1) y el patio abierto (ámbito 2). En él se abre un vano, enfrentado a la puerta de la entrada del muro oeste, con una luz máxima de 1,40 m. A escasos $20 \mathrm{~cm}$ al norte del vano se documentó una mancha de carbón de un listón o tablón asociado a algunos clavos y varios herrajes de hierro atribuibles a una puerta de madera.

El acceso a la sauna debió practicarse por la pared este donde se observó durante la excavación una zona deprimida con una coloración más oscurecida fruto del tránsito de entrada y salida.

\subsection{Estructura no definida (ámbito 6)}

La estructura, de 3,43 $\mathrm{m}^{2}$, consta de dos muros realizados con la misma técnica que el resto de los muros del edificio, de 35 a $40 \mathrm{~cm}$ de grosor (Figura 2). Al este no conserva lienzo murario si bien la capa de cascajo documentada parece indicar que estaría acondicionada. En su interior se dispone una torta de arcilla amarilla de 1,98 $\mathrm{m} \times$ 1,57 m y 50 cm de potencia, en cuyo centro se documentó una cubeta circular de 107/101 cm de diámetro $(80 / 87 \mathrm{~cm}$ en la base) y $40 \mathrm{~cm}$ de profundidad máxima.

La cubeta aparecía rellena con varias lajas de arenisca dispuestas unas sobre otras que debieron conformar una especie de recubrimiento interior de piedra. Bajo esta se recuperan varios objetos de metal: un clavo, una grapa de hierro, varios fragmentos de bronce, dos afiladeras y varios cantos de cuarcita o arenisca similares a los del vaso de la sauna.

\subsection{Cenizal (ámbito 7)}

Esta área se encuentra situada al oeste del edificio (Figura 2), junto a un pasillo-rampa elevado, bajo cuyo derrumbe se recuperó un objeto de hierro de unos $35 \mathrm{~cm}$ con forma apuntada, enmangue tubular, sección del astil cuadrangular y una única aleta lateral, que puede ser identificado como un pilum incendiarium, similar, aunque de mayor tamaño, a algunas plainrods militares romanas conocidas en Šmihel (Eslovenia) (HORVART, 2002: 186) (Figura 12 y 13). La pieza conservaba restos del astil datado en 2080 \pm 30 BP (Poz-45375), concretamente entre en el periodo del 191 al 38 a.C.

A simple vista la fecha se aleja del Bellum Cantabricum y nos obliga a ver en el objeto algún tipo de herramienta prerromana. No obstante el exiguo margen con respecto al conflicto bélico (29 - 19 a.C.) y su clara tipología, nos inclinan a relacionarlo con la ofensiva romana ya documentada en el castro (FERNANDEZ VEGA y BOLADO DEL CASTILLO, 2010).

Es de destacar por último la aparición de diversos fragmentos de cerámica como un vaso y un borde realizados a mano y de cocción alternante, o un borde de cerámica oxidante a torno perteneciente a un cuenco carenado (Figura 6, 1; 6,3 y 6,4) con paralelos cercanos en el castro de Las Rabas (Cervatos, Cantabria) (GARCIA GUINEA y RINCON, 1970: Fig. 11,7; Lam. X,10 y XI,5).

\subsection{Pasillo-rampa (ámbito 8)}

La zona externa, al noroeste y oeste del edificio, fue adecuada mediante un aterrazamiento en dos niveles para permitir el acceso y circulación del servicio (Figura 2). La roca madre existente junto a la puerta de entrada noroeste fue retallada suavizando su buzamiento natural norte-sur. No aparece material arqueológicamente destacable.

El muro sur de la gran sala (ámbito 1) se prolonga hacia el oeste por el exterior del edificio dejando al descubierto un nuevo muro paralelo al del cierre occidental. Dista de éste unos $125 \mathrm{~cm}$ y conforma un pasillo rampa de tránsito entre el ámbito 7 y la puerta de entrada noroeste. El murete está realizado con mampuestos sin argamasa.

\subsection{Espacio no definido (ámbito 9)}

El último espacio del edificio es el correspondiente a la terraza más baja, excavada sólo perimetralmente, cuya superficie útil es de 82,07 m (Figura 2).Los muros son iguales al resto del edificio con mampostería al exterior y el interior formado por tierra y cascajo. Bajo el lienzo de mampostería se observa la cimentación realizada con bloques informes de medio tamaño. Los esquinales sureste y suroeste de los muros son redondeados.

Entre los materiales recuperados destaca una hebilla de cinturón en "D" compuesta por una placa y aguja decorada y la hebilla (Figura 14). Su adscripción crono culturales confusa pues podemos encontrar para ella tanto paralelos en el mundo romano y militar romano relacionado con el periodo de conquista (FERNÁNDEZ VEGA y BOLADO DEL CASTILLO, 2010: 316, 318, 320 Y 322. BOLADO DEL CASTILLO et alii, 2010: 90-91), como en contextos prerromanos: tumba 140 de la necrópolis celti- 


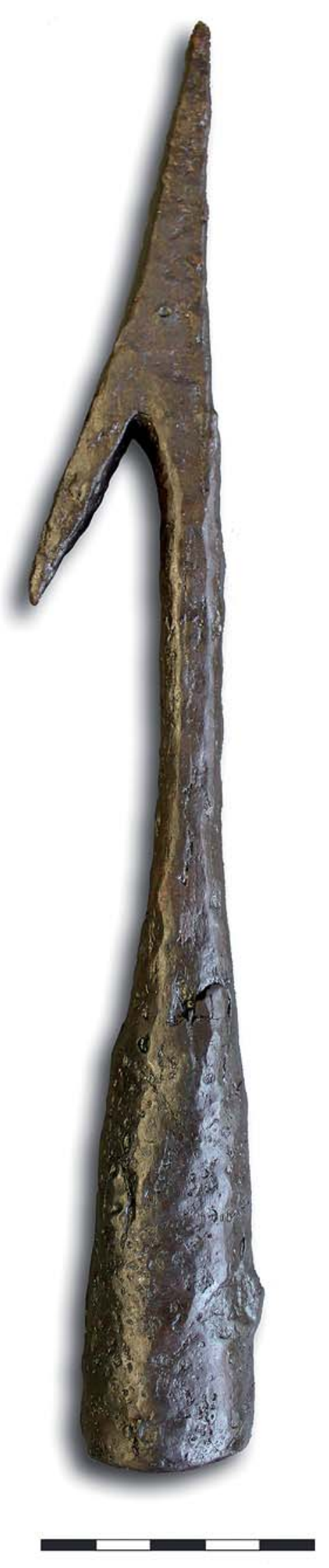

Fig. 12. Pilum.

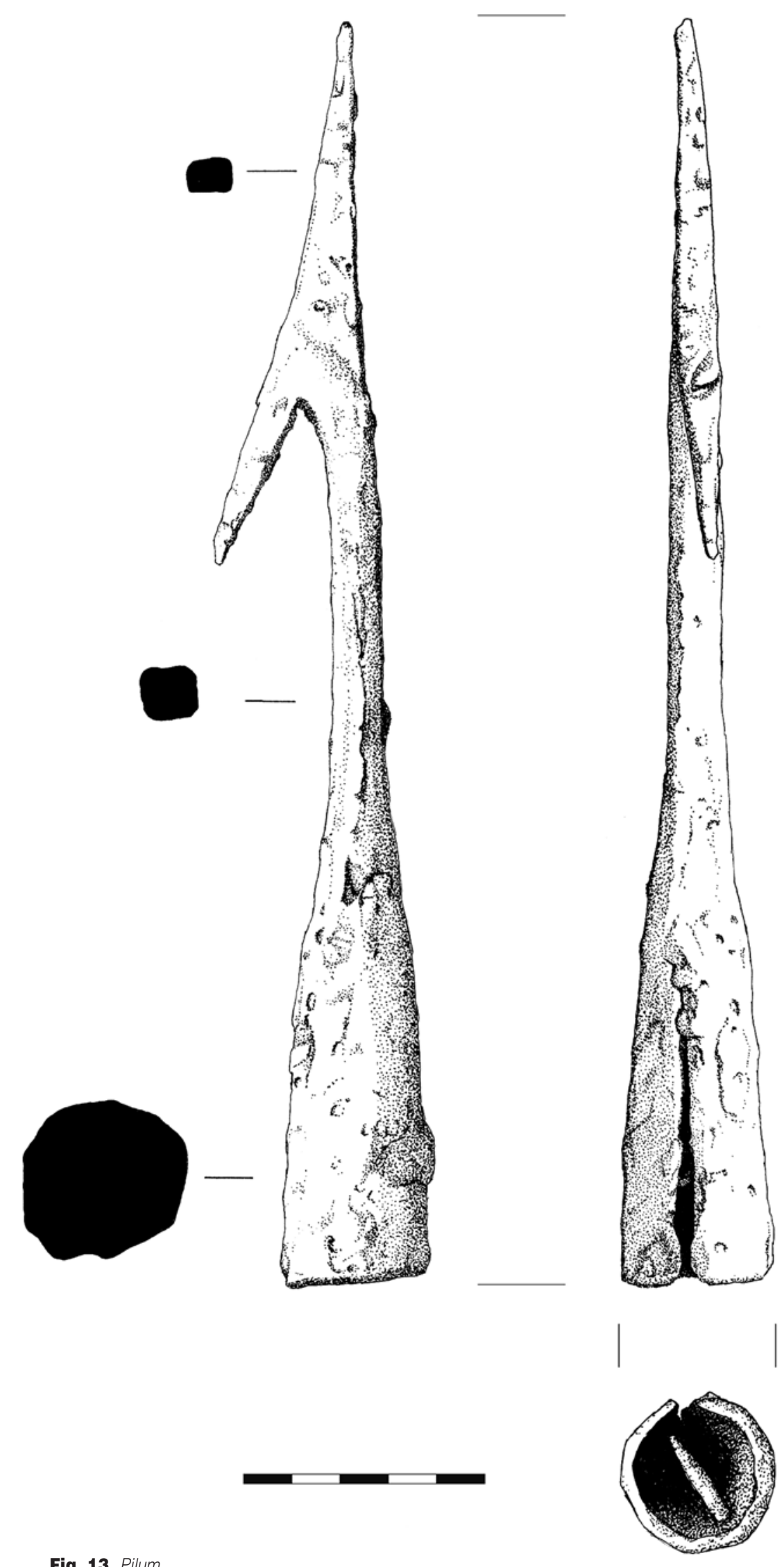

Fig. 13. Pilum. 


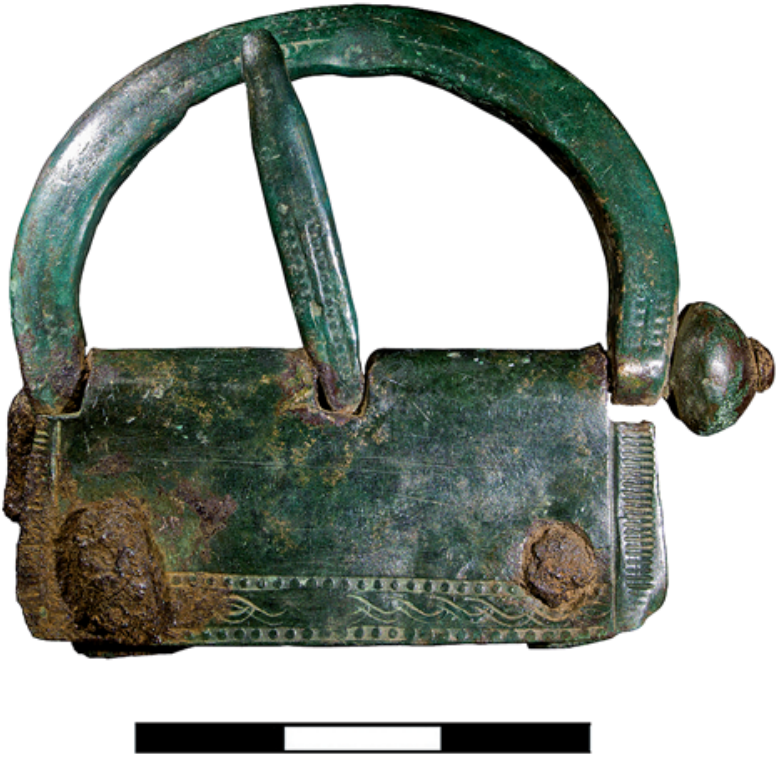

Fig. 14. Hebilla / Buckle.

bérica de Numancia (JIMENO et alii, 2004: 147), Monte Bernorio (TORRES, J.F.; MARTÍNEZ, A. y LUIS, S. de 2012: 146), necrópolis del Burgo de Osma (tumbas 18-MAN y 12 MAN) adscribibles al s. III/II a.C. (LORRIO, A.J. 1997: 223).

\section{3.- CARACTERIZACIÓN FUNCIONAL E INTER- PRETACIÓN DEL EDIFICIO}

La estructura arqueológica exhumada posee una envergadura muy ambiciosa para los habituales proyectos constructivos en el panorama arqueológico castreño. La erección de murallas constituye de manera habitual la empresa constructiva más importante en un sistema de poblamiento que no conoce el urbanismo, aunque sí manifiesta planteamientos urbanísticos elementales. La creación de pequeñas calles o callejones que discurren entre casas exentas y la habilitación de terrazas para hacer frente a lugares de topografía difícil y en pendiente, suelen constituir los aspectos de planificación detectables en poblados, sin una organización del espacio urbano, jerarquizada por calles, más allá de los aspectos más perentorios, los derivados de las puertas y accesos del propio poblado. Todo esto, referido al mundo prerromano del noroeste, sin que desde el ámbito cántabro se pueda predicar de manera fehaciente nada en absoluto: no se han practicado excavaciones en extensión sobre yacimientos de la Edad del Hierro que permitan sostener estas afirmaciones preliminares.

En el caso de Santa Marina la plataforma excavada era perfectamente discernible en la superficie del yacimiento como obra antrópica de envergadura. La excavación, durante buena parte del avance de los trabajos, se ha singularizado por la ausencia de material arqueológico de cronología discernible o que se pudiera adscribir inequívocamente a un horizonte histórico dentro del propio edificio, si bien los indicadores constructivos desde un pri- mer momento apuntaban a tecnología prerromana: la técnica de muros mataterreros y especialmente, el manteado. La certificación vendría de la mano de las dataciones radiocarbónicas.

La relativa escasez de material arqueológico junto con la envergadura de la intervención constructiva, avalaban la teoría de un edificio público, de naturaleza comunitaria o colectiva, dado que no había elementos domésticos o evidencias de procesos productivos. En estas coordenadas, podría tratarse de una plaza análoga a las que se identifican en castros asturianos. El otro tipo de edificio complejo que se ha documentado por ahora son las saunas, y de hecho, esta era ya la hipótesis valorada como más probable ante la apreciación de un espacio ligeramente deprimido y de componente arcilloso que se percibía en superficie antes de comenzar a excavar la cubeta de la sauna, y que confirmaría finalmente esta idea.

Sin embargo, la valoración del edificio requiere muchas matizaciones.

\subsection{La naturaleza y uso de la construcción}

La edificación se levanta sobre una terraza artificial delimitada en tres lados - este, sur y oeste- por los muros de contención, que soportan el material de tierra y cascote que forma el relleno en pendiente. No ha sido excavado en su totalidad pero, hasta donde se ha observado, toda la parte sur no albergaría otras estructuras arqueológicas, dado que corresponde a la pendiente que permite alcanzar la cota de nivelación sobre la que se levantó el edificio en el sector septentrional. Por otro lado, al norte de toda la estructura, el muro de ese flanco contiene un nivel de relleno más alto en el sentido de la pendiente. Se trata pues de una edificación en terraza, flanqueada al norte por un relleno de cota alta y al sur por el relleno en cota más baja, lo que se traduce en un una construcción parcialmente enterrada o encajada en el terreno, y que invita a presuponer una estructura de cubierta en plano inclinado único, buzando de norte a sur en el sentido de la pendiente y que contaría con algún punto de apoyo central a modo de pie derecho en el ámbito 1.

La plataforma que sirvió de suelo al edificio se valió de la roca madre, someramente rellenada de tierra para nivelar, pero los constructores tuvieron que reconocer previamente el sustrato rocoso puesto que las dos estructuras excavadas en la roca -ámbitos 3 y 4-, se alojan muy próximas a los bordes de escalones de la roca natural. Este fue un factor determinante de la localización, del aprovechamiento del espacio y de la estrategia de rellenos en el lado sur con muros de contención de la terraza: había que contener el terreno pero éste sólo cargaba con el muro de cierre sur del edificio; los aprovechamientos interiores del espacio y las estructuras de contención -ámbitos 3 y 4- se sirvieron de la roca natural para no derivar empujes hacia la zona de rellenos.

El primer ámbito de la construcción - $n^{\circ} 1$-, con acceso por el oeste, posee técnica de paramentos de piedra careados, hacia el interior en el norte y hacia el 
exterior en el este y el sur. Los muros parecen haberse engrosado con material de construcción pétreo y con tierra. La distribución del manteado que puede apreciarse en el plano remite a un revestimiento de paredes con esta técnica que iría adherido a las piedras del muro, dado que los reversos del manteado no muestran las características improntas del zarzo o del entrelazado de varas, pero sí de hierbas, tablas y piedras. En la estancia 1, el suelo de roca apareció coloreado en un intenso color rojizo-granate, lo que delata un episodio de destrucción por incendio que, probablemente, hizo desplomarse la cubierta de material leñoso sobre el pavimento mientras ardía, meteorizando la roca por efecto del intenso calor. Este efecto del calor fue confirmado por los análisis realizados por geólogos de la Universidad de Cantabria. Otras hipótesis, como la de fuegos encendidos sobre la superficie de la estancia, se podrían descartar en ausencia de capas de cenizas.

En el cuerpo constructivo cuadrangular en el que se inscribe el ámbito 1, la identificación de la cisterna $n^{\circ} 3$, cuyo relleno de agua parece quedar bien asegurado a partir de la apertura de su boca hacia la zona norte y oeste, permite reconocer la presencia de un atrio, un espacio descubierto. Se adivina siguiendo el plano de distribución de los hallazgos del manteado, y correspondería al ámbito $n^{\circ} 2$. La presencia de algunas piedras con aspectos de losas, y con piedras de cimentación bajo ellas en algún caso, para apoyo de pies derechos, permite intuir la presencia de una estructura lígnea de postes de madera, trabados entre sí por las vigas de la cubierta, y unidos por muros revestidos de manteado. Es probable que la comunicación entre los ámbitos 1 y 2 se realizara por el centro del lado oeste, donde se halló una bisagra.

En el lado norte del ámbito 2 un corredor cubierto permitiría el tránsito entre los ámbitos 1 y 5, separados por una puerta ubicada al oeste del ámbito 4. Ese corredor mostraría un tejadillo que vertería hacia el ámbito 2, de modo que la cisterna 3 se rellenaría con el agua de lluvia y desnieve captados en ese espacio. Sin embargo, el aprovechamiento de ese recurso se verificaría desde el interior del ámbito 5, es decir, la cisterna 3 captaría el líquido en 2 pero estaba trasdosada al otro lado del tabique, dentro del ámbito 5. Una perforación en la parte baja del tabique que delimitaba el atrio, permitiría el paso del agua. Los excedentes rebosarían y se evacuarían por el lado sur de la cisterna. No hubo estructuras de decantación antes del almacenaje del agua. No parece a priori destinado al consumo humano. El trasdosado hacia el ámbito 5 de la cisterna la cobijaba bajo cubierta y mejoraba la conservación del agua. El hallazgo de los elementos metálicos de un caldero en el ámbito 2 lógicamente entronca con esta estructura. El clavazón en el interior del pozo aludiría a una estructura interna de madera que soportaría el enlosado interno del brocal.

El ámbito 5 resulta muy complejo en cuanto a su interpretación por la indeterminación del cierre por el sur, si bien contiene, dentro de su volumen constructivo, los ámbitos 3 y 4 bien caracterizados. La presencia de la cisterna 3 y la disponibilidad de agua se tornan en un factor signi- ficativo. La asociación de la cubeta $n^{\circ} 4$ con el calor permite identificar funcionalmente todo el espacio y el conjunto de la edificación.

La identificación del ámbito como sauna, era una hipótesis a verificar que quedó perfectamente contrastada desde el momento en que se excavó el fondo de la estructura que contenía la fosa o vaso rectangular central con las piedras rubefactadas. Ineludiblemente emerge el paralelo con los vasos que se han ido hallando en las saunas asturianas y galaicas. Se trata de vasos de losas de piedra pero siempre asociados al calor recibido directamente del horno adyacente. Así, el de la sauna de Coaña 1, realizado con losas de pizarra dispuestas sobre la roca madre tallada, con dimensiones de $160 \mathrm{~cm} \times 65 \mathrm{~cm} \times 40 \mathrm{~cm}$ (JORDÁ, 1983: 23; VILLA, 2000: 100); la cámara de vaporización del castro de Chao Sanmartín (Grandas de Salime), también realizada con losas de pizarra dispuestas sobre una superficie monolítica, con unas dimensiones de 170x50x40 cm (VILLA, 2000: 110); la caldera de Monte Castrelo de Pelóu (Grandas de Salime) de 128x55 cm (VILLA,2011: 27); la caldera de Os Castros de Taramundi efectuada con losas verticales para habilitar una cubeta rectangular de 163×66 cm (MENÉNDEZ y VILLA, 2009: 461); el contenedor realizado en Punta Dos Prados (Ortigueira) con losas, de unas dimensiones de 160x66×45 cm (RÍOS, 2000: 105); el de Pendía 1 (Boal) también excavado en la roca y forrado con losas de pizarra con dimensiones de 150x65×46 cm, que tiene la peculiaridad de estar conectado a una canalización de desagüe (VILLA, 2000: 105, RíOS, 2000: 102). Queda pendiente en todos los casos tal vez, una reconsideración acerca de la operatividad del dispositivo de la sauna y un razonamiento acerca de si estas cubetas contenían agua o se usaron de un modo alternativo, teniendo en cuenta otros factores como la altura de techos para valorar la eficiencia y el rendimiento adecuado de la instalación de la sauna. Se denomina a estos vasos calderas, y esto induce a pensar que rellenaban el hueco con agua que luego se evaporaba, sin embargo habría que valorar si funcionaban con piedras precalentadas, en cuyo caso sería mejor llamarlas estufas. La ausencia general de canalizaciones de desagüe en la práctica totalidad, invita a revisar estas interpretaciones.

En el caso de Santa Marina las medidas del vaso de $177 \times 70 \times 120 \mathrm{~cm}$ son similares a las citadas, sin embargo difiere sustancialmente en la trasmisión del calor. Aquí se realizó de forma exógena, es decir, se calentaban las piedras previamente para verterlas al interior del vaso, mientras que en el caso de las saunas del NW había un horno inmediato a las paredes del vaso. En todo caso se ha señalado la existencia de cantos rubefactados asociados a algunas de ellas. Cantos rubefactados de este tipo han sido señalados en el fondo del horno de la sauna de Coaña 1 (JORDÁ, 1983: 23, VILLA, 2000: 100), pero también en las saunas galaicas de Briteiros, Galegos y Freixo que han sido relacionados con la generación de vapor mediante la aspersión de piedras candentes (CARDOZO, 1932: 19; SILVA, 1986: 59; TABARES, 1997: 34 y RÍOS, 2000: 101). 
Otros paralelos, habría que encontrarlos en los fulachta fiadh irlandeses, con dataciones que van desde el 1900 al 500 a.C., donde se observan vasos rectangulares de piedra o forrados de madera, de escasa altura e insertos en estancias circulares o semicirculares cubiertas con materiales perecederos. No está definitivamente establecido el uso de este tipo de estructuras como saunas, y se debaten otros posibles usos como estructuras para cocinado, extracción de grasa, procesado textil, elaboración de cerveza, fabricación de barcos, producción de mantequilla, tareas metalúrgicas o teñido de pieles (O'DRISCEOIL, 1988: 672; GRABOWSKI, 2008). Las hipótesis expuestas son muchas, y evidencian una caracterización formal de las estructuras poco concluyente y de interpretación abierta, pero es probable que algunos ejemplares sí que correspondieran a saunas (BARFIELD y HOODER, 1987).

En este punto resulta ineludible recordar una información que transmite Sidonio Apolinar acerca de los galorromanos en la zona del río Gard a mediados del siglo V d. C.: "... se excavaba una fosa cerca de una fuente o río en la que se arrojaban un montón de guijarros ardientes; después, mientras la fosa acumulaba el calor, se la cubría de una cúpula con ramas flexibles de avellano entrelazadas en forma de hemiesfera; además se echaban por encima coberteras cilicias (de pelo de cabra) para cerrar los huecos entre las ramas y eliminar la luz, conservando en su interior el vapor saliente que se producía por la aspersión de agua hirviendo sobre las piedras candentes (...) Se producía una sudoración muy saludable, rodeados y envueltos por la emanación de un vapor sibilante." (ALMAGRO y ÁLVAREZ, 1993: 195). La cita es suficientemente elocuente acerca de lo sencillo que podía ser resolver una sauna de forma perentoria, y de las virtualidades salutíferas que se le confería.

En lo que respecta a Santa Marina, dos aspectos constructivos son especialmente dignos de consideración por lo que entrañan para la comprensión de la sauna. El primero concierne al voluminoso aporte de arcillas con que se revistió todo el habitáculo excavado en roca. La observación de la sección permite comprobar que, más que un revestimiento, fue en zonas un relleno y, en general, el auténtico material de construcción con que se modeló el habitáculo. Cabría la posibilidad de haber pensado en una estrategia de impermeabilización para evitar fugas de agua en una cisterna de contención, pero no hay desagüe de evacuación. No contenía agua. En realidad la arcilla cumplía otra función. Hoy las saunas ofrecen un revestimiento cálido y confortable, de madera, que guarda y devuelve el calor. Esa misma fue la función del grosor de las paredes de arcilla. Seca y compacta se comportaría al modo del material testáceo de los hipocaustos romanos: absorbe el calor durante horas y lo reverbera lentamente, irradiándolo y garantizando que, a condición de que la cubierta garantice el hermetismo y el acceso a la sala se cierre, la sensación térmica cálida persista durante horas y se reavive con aspersiones de agua sobre las piedras.

El segundo aspecto constructivo relevante concierne a la habilitación del vaso, de gran formato, excavado en roca para alcanzar una profundidad que oscila desde al menos $1,77 \mathrm{~m}$. en el lado norte a un metro en el lado sur, dado el buzamiento de la pendiente de la roca natural horadada. En el fondo, el nivel 9, de unos $20 \mathrm{~cm}$ de espesor, corresponde al material que quedó de los procesos de calefactado, pero esto implica que por encima, hasta el nivel del borde del vaso conservado resta más de 1,5 m operativos. Evidentemente se trataba de una estructura de vocación claramente críptica y esto se explica lógicamente por la necesidad de mejorar el rendimiento calorífico de la instalación. En una sauna actual, puede verse un espacio reducido incluso cuando el origen del calor sea una fuente constante de energía, la resistencia eléctrica regulada por termostato. Hoy mismo, sobre la resistencia se colocan las piedras que almacenan e irradian de manera permanente y más homogénea el calor. Son las piedras las reguladoras de un calor más constante. En el caso que nos ocupa, la fuente de calor hubo de estar fuera: la cubeta impedía hacer fuego y, dentro de una depresión tan profunda, no había tiro para hacer arder combustible. Esto explica la ausencia de cenizas. Se aportaban pues las piedras ya calentadas y se depositaban en el fondo de la cubeta o estufa. Se halló un buen número en el fondo de la misma con carbones adheridos.

La otra parte de la estrategia de funcionamiento tiene que ver con el factor altura. En una sauna actual, no sólo el habitáculo es reducido, sino que el techo está bajo y los bancos sobre los que se toma la sauna se elevan del suelo de modo que el usuario aprovecha el calor de las capas de aire altas del habitáculo. Seguramente esto es lo ocurrido aquí, y para eso sirvió la estructura críptica tallada en la roca. Sobre los bordes de la fosa rectangular en cuyo fondo estaban las piedras previamente calentadas, es decir, la estufa, se sentarían los usuarios, quizá con las piernas hacia el fondo de la estufa, apoyadas en una repisa de madera. De esta manera, no es preciso suponer que las paredes exteriores de la sauna tuvieran mucha más elevación que la que conservan. Al modo en que las pedras formosas clásicas de las saunas castreñas galaicas obligaban a reptar para acceder a la cámara de calor, en este caso, una gatera en el borde de arcilla superior del vaso de la sauna permitiría entrar y deslizarse sobre el escalón que circunda la fosa de la estufa para sentarse. El calor se produce en el fondo del suelo pero asciende en vertical por la fosa bañando al usuario en su ascenso y concentrándose en las capas altas del habitáculo que es donde se encuentra sentado el bañista. El resto es efecto del vapor de agua. Las aspersiones sobre las piedras calientes permiten producir el vapor que va ascendiendo y hace incrementar la sensación térmica y la humedad ambiental para intensificar la sudoración.

Dentro del habitáculo no había mucho espacio pero en derredor del espacio rectangular de la fosa de la estufa -de 1,77 x 0,70 m- podrían encontrar acomodo al menos cuatro personas. Los bordes conservados de la olla o vaso de la sauna aún se yerguen 0,77 m por encima del borde de la estufa. No se necesitaría mucha más altura, quizá 30 cm., para cerrar por encima la sauna y habilitar la gatera de acceso con trampilla de cierre. Un bastidor de madera, 
del que se encontraron los clavos, fortalecería el borde de la estufa para evitar su desplome por el uso y el peso de los bañistas, y se crearía probablemente una especie de banco, quizá con base de madera, al menos en el lado norte del borde de la estufa pues, por el lado sur, la pared de arcilla se muestra más vertical.

En cuanto a su articulación con el ámbito 5, nos inclinamos a pensar que la sauna fue un habitáculo específico y cubierto dentro de otro ámbito techado aún mayor. En primera instancia, la cubierta de la sauna propiamente dicha podría haberse verificado con material orgánico perecedero de tipo vegetal o incluso con pieles como decía Sidonio Apolinar y como avalan los paralelos etnográficos e históricos pues, a fin de cuentas, como puntualizarían Barfield y Hodder (1987, 372), basta con una fuente de calor y un espacio cerrado. En un artículo ya clásico que postuló la identificación de las burnt mounds como saunas, verificaban que podían adoptar la forma de construcciones semisubterráneas de estructuras abovedadas o de cubiertas cupuliformes, por aproximación de hiladas de losas, o como las que hacían los sioux con una trama de varas y pieles -análogas a las galas que describía Sidonio Apolinar-, siendo el techo bajo un factor clave de la adecuación. Se trata lógicamente de aprovechar un reducto envolvente bajo el calor que migra a la zona más alta de la estructura por el efecto de ascensión del aire cálido que se dilata y pesa poco. En este punto, es ineludible recordar el aspecto hipogeo que manifiestan algunas saunas castreñas como Pendia 1 (VILLA, 2000: 104; 2011: 21), cuya altura de la cámara absidal es de 1,8 en el centro de la bóveda de cuarto de esfera. En general se ha resaltado además que se trata de construcciones semi-hipogeas parcialmente excavadas en tierra o talladas en piedra y completadas con muros (ALMAGRO y MOLTÓ, 1992: 70).

Como evidencias de la cubierta quedarían en el relleno de la cubeta de la sauna los niveles 2, 3, 4 y 6. El primero, más superficial corresponde a piedras que se desplomaron de canto y apiladas -también el nivel 6 registrado en el relleno de la estufa-. Una primera hipótesis sería valorar una estructura de bóveda de cuarto de esfera que parece intuirse a partir de la planta de tendencia semicircular de la sauna aunque faltaría piedra. El lado recto de la bóveda en su sector más alto correspondería al muro exterior del edificio por el norte. Sobre ese sector norte, la pendiente del terreno ofrece una altura de cota mayor, que permitiría encontrar además un apoyo firme para los empujes de la bóveda. De este modo el sector norte de la cámara de la sauna tendría su área más alta y transitable por el norte. El nivel 3 con manteado remitiría al revestimiento de la bóveda y el nivel 4 en el que se registran gravas y cayuela quizá pueda derivar de la fracción fina decantada de entre las piedras de mayor tamaño, o remitir a un árido que se mezclara con las arcillas del revestimiento para otorgarle más fortaleza y perdurabilidad. No podemos excluir la opción de de una cubierta vegetal o formada por pieles.

En cuanto a la zona de acceso al interior de la sauna, dados todos los planteamientos previos, habría que iden- tificarla donde la bóveda adquirió mayor altura, pero, al tiempo, donde la gatera de entrada no rompiera la bóveda más que en la base, y evitara la pérdida del mayor calor posible que se concentraría en la parte más alta. Puesto que por el lado oeste, el corredor de acceso desde el ámbito 1 presentó la puerta, y enfrente la hombrera de la estructura de arcilla se eleva a la mayor altura, la alternativa lógica sería que la entrada se realizara por el este junto a la pared norte, donde, de hecho, durante la excavación se percibió una zona rebajada en la arcilla y una coloración más oscurecida de suelo pulido y ensuciado por rozamiento. En ese sector del ámbito 5, donde estaría la entrada a la sauna, el nivel del suelo de roca se halla más deprimido y mostró mayor relleno de tierra, lo que puede indicar que, en efecto, en ese sector se labró un acceso.

No se puede dejar de resaltar el hallazgo de las fíbulas en el fondo de arcilla de la estufa. Sugieren la idea del desvestido de los bañistas y apartan las posibles reticencias a reconocer una sauna en la estructura. Sin embargo, quizá puedan significar algo más en otra faceta: si los bañistas accedían vestidos al interior y se despojaban de la ropa dentro, esto parece distanciar la sauna de posibles connotaciones iniciáticas o rituales, que se conciliarían mejor con usuarios desnudos o a lo sumo con una túnica.

\subsection{Valoración de la ordenación}

La identificación de saunas en el Noroeste Hispánico deviene el referente lógico en el que circunscribir la sauna de Santa Marina. Siempre se ha destacado la presencia de dos núcleos o zonas de ejemplares, en la región galaica y el Navia (ALMAGRO y MOLTÓ,1992: 72; ALMAGRO y ÁLVAREZ SANCHÍS,1993: 186), lo que ha llevado a definir finalmente no sólo dos zonas sino dos tipos: el modelo termal bracarense, al sur del Miño, y el lucense, en el Navia junto con varios ejemplares gallegos que se han ido sumando (RÍOS, 2000: 96). También se les ha denominado tipos meridional y septentrional respectivamente (GONZÁLEZ RUIBAL,2006-2007: 572). La diferencia entre ambos modelos radicaría principalmente en la existencia de pedras fermosas en las meridionales o bracarenses, el bloque monolítico tallado con una gatera para entrar a la cámara de calor, y el añadido, en éstas también, de una estancia más: un atrio, la cámara y el horno, a las que se suma una antecámara o sala tibia -lógicamente precediendo a la cámara- (SILVA, 1986), que en las asturianas no estaría presente. Chao Sanmartín escaparía a esta síntesis si se acepta la propuesta de atrio-antecámaracámara-horno tal y como se ha interpretado (VILLA, 2011: 25), dado que los dos primeros ámbitos se encuentran parcialmente atrofiados y formalmente distorsionados.

En definitiva se trataría de contar con tres o cuatro ámbitos. A continuación sobrevienen las cuestiones de nomenclatura o terminológicas: ¿atrio o vestuario? ¿caldera u horno? A veces se trata de aspectos diferenciados claramente y otras de sinonimias, pero se puede convenir en hablar de atrio si se trata de un espacio descubierto, un cavum aedium en el que la captación de agua y la pre- 
sencia de un pilón ha llevado a hablar de sala de agua fría (GONZÁLEZ RUIBAL,2006-2007: 502) en clara analogía con los modelos termales romanos. La antecámara en ese mismo sentido sería la sala templada, la cámara sería la sala caliente y el horno albergaría el dispositivo de calor.

En lo que atañe a Santa Marina, seguiría el modelo más completo pero dislocado. Cuenta con atrio pero no se identifica en el primer ámbito. De hecho, si hubiera que aplicar un apelativo al primero de estos espacios sería el de vestíbulo o quizá sala de reunión, dada la envergadura de la misma: con una superficie útil de $61,1 \mathrm{~m}^{2}$ se distancia de los atrios que abren las saunas castreñas y que oscilan entre 13 y $20 \mathrm{~m}^{2}$. Se trata de salas descubiertas en las que se identifican pilas de agua fría rellenadas por medio de conducciones de agua procedentes de una fuente y no por acopio in situ de las precipitaciones (GONZÁLEZ RUIBAL,2006-2007: 572). El atrio de Santa Marina con 17,22 m² podría asemejarse por dimensiones a los galaicos pero no en lo que concierne a ubicación y funciones: la captación de agua es distinta y ha perdido el rol de vestíbulo.

En una disposición canónica, coherente con el modelo asturiano o lucense, más próximo en lo geográfico y lo cultural con el mundo cántabro, el ámbito 1 hubiera sido una antecámara. Difícilmente podríamos reconocerla como tal, por su desproporcionado tamaño y el distanciamiento que media, a través de un corredor que discurre por el norte del ámbito 2 -atrio-, hacia el ámbito 5. Específicamente las funciones vinculadas con la toma del baño se centran en este último espacio. Ni siquiera parece que podríamos pensar en un vestuario en el ámbito 1 o vestíbulo, pues las fíbulas halladas en la estufa indican que a la sauna se accedió con ropa. Sin embargo, el ámbito 5 pudo funcionar como vestuario.

La identificación de la antecámara ha de derivar en realidad de la de la cámara, y, en este caso, es evidente que la cámara corresponde a la sauna, identificada en el ámbito 3. Se infiere que en el ámbito 5 habría de hablarse de antecámara utilizada como cuarto de desenvolvimiento en relación con la sauna: en rigor podría decirse que se trata de una sala templada con dos usos discernibles, de vestuario y de depósito del agua -ámbito 3- necesario para las aspersiones. Ambas funciones se cumplirían en el sector oeste del ámbito 5, mientras que el sector este corresponde a un área de accesos. Él ámbito en general estaba muy alterado en cuanto a su realidad constructiva. Un gran derrumbe en el sur se explica como relleno de terraza, pero puede delatar muros de cierre no bien definidos. Por el norte la cabecera del edificio tiende a estrecharse y deriva en un muro más engrosado en la base porque pudo tener un segundo acceso al edificio retranqueado, protegido por un paravientos exterior que precedía a un suelo enlosado en el centro de la cabecera. El área al que conduce este acceso sería el correspondiente a la entrada agaterada de la sauna. En cuanto a la presencia en la cabecera de un segundo acceso, los ejemplares asturianos y lucenses lo refrendan de manera frecuente-Punta dos Prados, Coaña 1 y 2, Chao Samartín (RÍOS, 2000; VILLA, 2000)-
En una disposición convencional de los parámetros de las saunas castreñas de todo el noroeste, en el lado oriental del edificio, en la cabecera, debiera haberse encontrado el horno, la fuente de calor con forma absidal o ultrasemicircular. Así ha sido, pero no se puede garantizar que se trate del horno. Formalmente el ámbito 6 responde a un anexo semicircular en el momento de excavar los niveles, aunque ha perdido el muro este que cerraba en arco. Aparecía muy en superficie, apenas recubierto por la capa húmica y mostraba una cubeta en arcilla rellenada por lajas, lo que invitaría a pensar en un horno característico cubierto por la falsa cúpula y alimentado desde fuera (GONZÁLEZ RUIBAL,2006-2007: 574), o un forro de piedra para la cubeta. Con 2,66 m de ancho, las proporciones encajarían en los diámetros convencionales de los hornos, que oscilarían, según los planos que se han publicado, entre 1,2 m de Pendia 1 y 2,7 m para Sanfins. Sin embargo, no parece que se trata de un horno, dado que no está rubefactada la arcilla como le hubiera correspondido a un hogar, ni aparecieron cenizas, ni carbones... y además se formó en la arcilla un receptáculo circular que alcanza los $30 \mathrm{~cm}$ de profundidad y, por tanto, carente de tiro para el fuego. Tampoco resulta indiscutible que el muro que lo separa del interior poseyera un vano de comunicación. Considerando que se trata de una estructura modelada en arcilla y no meteorizada por calor, la opción más viable como interpretación lo relacionaría con contención de agua, quizá un labrum, algo característico de las salas de calor para aliviar la sed, pero esto supone desestimar para consumo humano el agua de la cisterna -ámbito 4- y una interpretación poco convencional. En consecuencia, lo habitual sería entender que se trató de un horno de cabecera, pero no se puede asegurar porque faltan indicios y por la forma en cubeta del dispositivo que no favorecería el tiro del fuego.

La alternativa, dado que no parecía estar donde cabría esperarlo, pasa por reconocerlo en la estructura semicircular exterior al edificio en el extremo opuesto, en el oeste. No se ha acabado de excavar, pero el cenizal y los indicios de alteración de los materiales litológicos así lo indicarían. Por lo demás, no tiene nada de especial este dispositivo alternativo de calor exógeno: Estrabón hablaba de los lusitanos que habitaban en las inmediaciones del Duero y que tomaban "baños de vapor que se desprende de piedras candentes" (III,3,6). Estas piedras caldeadas se manipulan con pinzas de madera (BARFIELD y HODDER 1987, 372) y se podían mover del horno a la sauna, como de hecho parece que fue frecuente el territorio galaico: los cantos y piedras quemadas en los hornos y cámaras de Briteiros y Galegos y la acumulación de carbones y cenizas en la parte exterior, contigua al atrio, al menos en seis casos (ALMAGRO y MOLTÓ, 1992: 75), así lo probarían.

\subsection{Valoración del proyecto constructivo}

En lo que concierne al establecimiento de un emplazamiento relativo para este edificio en relación con el resto de las saunas castreñas, la figura 15 se torna muy elocuente. Un primer aspecto a destacar tiene que ver con la complejidad constructiva: el conjunto de saunas meridio- 
nal o bracarense manifiesta una cierta homogeneidad en cuanto que, a simple vista, cada ejemplar parece haber surgido de una yuxtaposición de estancias que se ordena en un eje axial y con un criterio de tránsito secuencial. En primer lugar se localiza el atrio transversal, el ámbito más amplio, y a continuación la sucesión antecámara-cámarahorno ultrasemicircular. En cada estancia se nota una ruptura de muros, una solución de continuidad, como si cada ámbito se construyera apoyado sobre el anterior pero no por compartimentación.

El conjunto de saunas del norte denota sin embargo otra técnica: al menos el horno o caldera y la cámara son fruto del mismo empeño constructivo coherente y decidido, que queda compartimentado. El añadido vendría dado por la antecámara o el ámbito de acceso que es fruto de una yuxtaposición de una estancia - o dos en Chao Samartín-, e introduce una entrada lateral, no frontal, provocando un eje acodado en la ordenación.

Desde estos parámetros de valoración, es evidente que la sauna cántabra de Santa Marina responde a una complejidad constructiva de planificación superior. El acceso principal por el oeste -A en el plano- deriva en un eje marcado por el corredor que se crea al norte del atrio 2. Una puerta controlaba el acceso al ámbito 5 -B en el plano- y la entrada a la cámara de la sauna se practicaba por el extremo opuesto, por el lateral este. Podría tratarse de matices pero denotan una mentalidad y una sofisticación en cuanto a la concepción del proyecto, creando un espacio de recepción de gran tamaño -ámbito 1- y habilitando un atrio -ámbito 2- para captación de agua de escorrentía en posición lateral, que carecen de paralelos, de manera que la ejecución del edificio no sólo implica compartimentación, sino además articulación de ámbitos y un pragmatismo funcional más evolucionado. El patio se localiza centrado entre ambas estancias ( 1 y 5) lo que indica que el edificio fue pensado y planificado antes de su construcción.

Una segunda entrada al edificio se practicó por el lado oriental -C en el plano-, pero se antoja más bien una entrada secundaria por su tamaño muy reducido, protegido tras un tabique paravientos y describiendo un sentido de giro completo, de $180^{\circ}$, en lo que hubo de ser una estrategia para evitar la fuga de calor de este ámbito 5 que servía de antecámara. Un referente al segundo acceso se podría entrever en los accesos laterales al horno en las cabeceras de algunas saunas del norte pero tenía que ver con la alimentación de la fuente de calor.

Otro aspecto especialmente reseñable, y que la lámina documenta de manera evidente, atañe a las proporciones del edificio. Se ha escrito para las saunas que su longitud rara vez sobrepasa los 12 m y que su anchura máxima, que normalmente corresponde al atrio, no supera los $6 \mathrm{~m}$ (SILVA, 1986: 55; ALMAGRO y MOLTÓ,1992: 70). La sauna de Punta dos Prados llegaría a 13,4 m de longitud y en cambio Santa Marina muestra un edificio de 24,25 m de longitud y alcanza un ancho en su sector occidental de 16,3 m para generar una planta de 303,74 $\mathrm{m}^{2}$ construidos.
Recientemente Ángel Villa ha enfatizado la presencia de "casas de asamblea" en castros asturianos con dimensiones de $45 \mathrm{~m}^{2}$ en Os Castros o Mohías, y superando los 60, 70 y $80 \mathrm{~m}^{2}$ en Coaña, Pendia, Pelóu y Chao Samartín (VILLA, 2011: 41), lo que a su vez encontraría un referente en castros portugueses (SILVA: 1986, 53) y guardaría relación con las necesidades sociales de relación de las comunidades castreñas. Entre estas casas de asamblea y las saunas se observa una vinculación (VILLA, 2011: 41) derivada de una relación de proximidad espacial que en casos como el Chao Samartín resulta ser de inmediatez colateral.

En Santa Marina, el ámbito 1 ocupa 61,1 $\mathrm{m}^{2}$ y podría relacionarse por analogía con esas casas de asamblea. Valorado así, en todo caso, se trataría entonces de una modalidad distinta de resolución de las necesidades de espacios comunitarios, ensamblando en un único proyecto constructivo de iniciativa colectiva, a juzgar por el aterrazamiento del espacio y la envergadura del proyecto, las funciones de reunión y de sauna. Esta dualidad habría quedado enfatizada además por una faceta constructiva importante: el conjunto de los ámbitos 1 y 2 se resolvió con técnica de muros mataterreros cuyos paramentos se enlucieron con manteado, y tabiques de manteado en el atrio, pero el recinto que modelaba el ámbito 5 parece haberse erigido todo ello en piedra a juzgar por los derrumbes, sobre todo en el lado sur, y en coherencia, se diría, con lo habitual en las saunas. Sin embargo, la unidad del proyecto constructivo de todo parece quedar atestiguada por el escaso espesor y la técnica de manteado de los tabiques del atrio, que no parecen haberse previsto como muros exteriores de carga, sino como divisorias de compartimentación interna.

Nada más podemos añadir respecto al uso de este ámbito 1 a falta de hallazgos arqueológicos sintomáticos, pero, entre los astures, se ha destacado que la gran cabaña de Pendia registró un lote de hachas pulimentadas y fragmentos de un caldero de bronce con remaches que remitirían a aspectos rituales y al uso de estas construcciones para festines y celebraciones comunitarias (VILLA, 2011: 42). Sería prolijo a partir de aquí avanzar por el camino ya transitado por otros autores (ALMAGRO y MOLTÓ, 1992:ALMAGRO y ÁLVAREZ SANCHÍS,1992; GONZÁLEZ RUIBAL,2007) acerca de las posibles funciones rituales de las saunas en primera instancia, pues nada nuevo se puede aportar por nuestra parte en materia de hallazgos. Rituales iniciáticos, lugares onfálicos relacionados con ritos ctónicos y creencias sobre el mundo subterráneo infernal, deidades de las aguas... todo ello son aspectos de un ámbito religioso y de creencias constatado, y aceptablemente conexionado con las saunas, pero se soportan más por acumulación de referencias literarias y de erudición que por certificación de contraste sobre el terreno. Si algo pudiera tener en Santa Marina unas connotaciones distintas sería el hallazgo en la estufa y en el relleno de la sauna de un buen número de afiladeras y manos de molino, pero no podemos otorgarle a priori una interpretación ni un significado trascendentes, de sentido ritual. A priori, una sauna se concibe como un baño específico con dos posibles funciones añadidas: la de socialización si es compartida, y seguramente lo fue, pues el dispendio de me- 
dios que requiere en el contexto social de procedencia no se antoja una práctica privada, y la salutífera quizás, a juzgar por lo que autorizaba a entender Sidonio Apolinar, y por los estímulos y reacciones que provoca el baño de vapor en el cuerpo, más allá de la vertiente higiénica. Si se acepta la interpretación de casa de asamblea para el ámbito 1, la dimensión de socialización se refuerza para todo el edificio, y la ritualización de las prácticas deviene más probable, pero en este caso, la interpretación ctónica parece más coherente con la cavidad excavada, y la relación con deidades de las aguas lo sería menos. Por lo demás, los hallazgos de fíbulas dentro se concilian difícilmente con rituales de iniciación a los que el iniciando habría de concurrir despojado de ataduras.

El otro factor realmente llamativo sería la envergadura ya destacada del edificio, que supera cualquier expectativa de una iniciativa privada en un contexto prerromano y que, como demuestra la figura 15 , excede de manera desproporcionada las saunas conocidas en todo el Noroeste. Por este motivo, se torna muy acertada la hipótesis de la asociación que, cuando se ha formulado para los ejem-
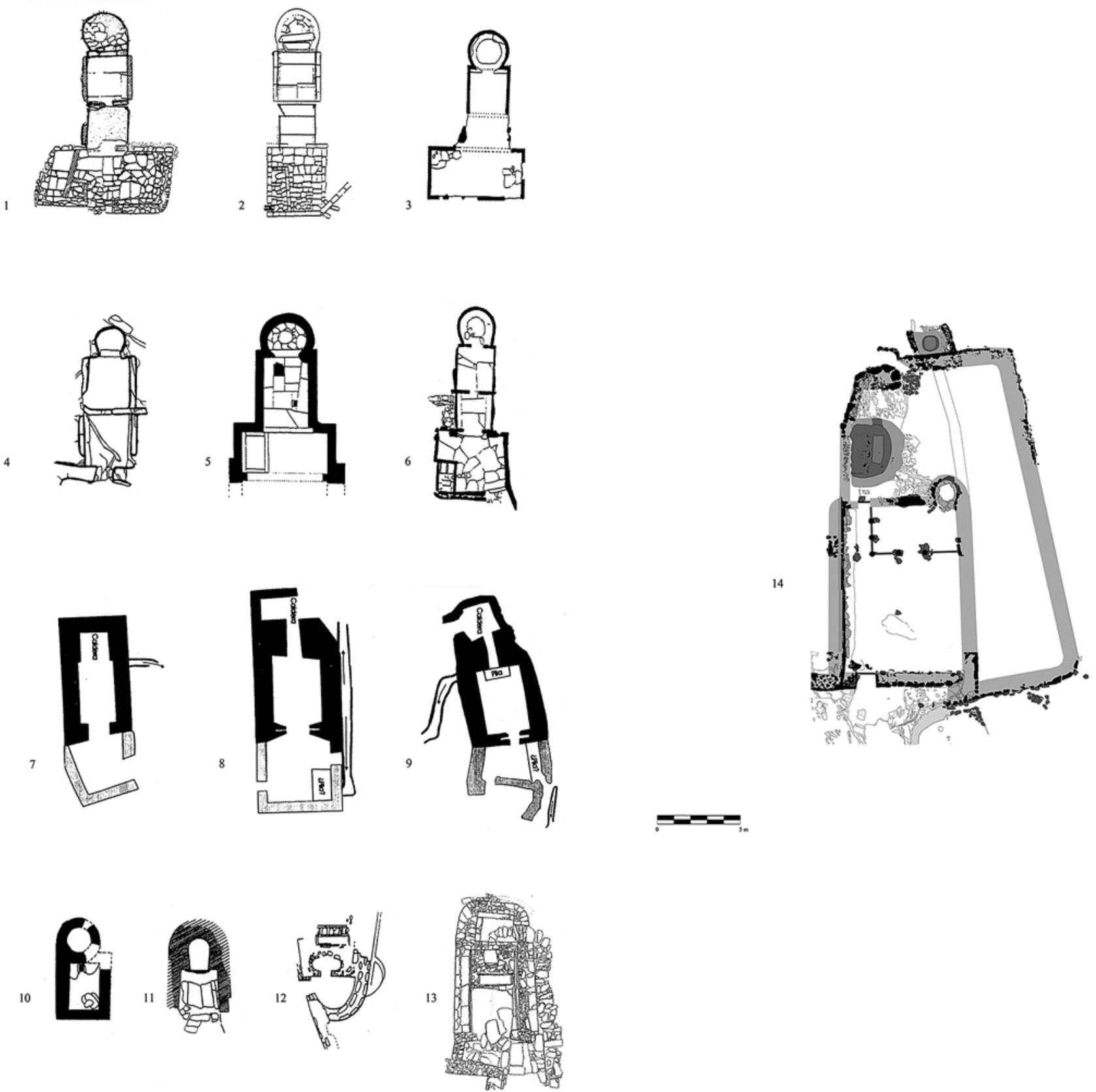

Fig. 15. Saunas asturianas, gallegas y de Monte Ornedo: 1) Sanfins, 2) Briteiros, 3 )Monte da Saia, 4) Tongóbriga, 5) Armeá, 6) Galegos, 7) Pendia, 8) Coaña 9) Fazouro, 10) Borneiro, 11) Coaña, 12) Pendia, 13) Chao Sanmartí, 14) Monte Ornedo. Elaborado a partir de González Ruibal 2006 / Asturian and galician saunas and Monte Ornedo sauna: 1) Sanfins, 2) Briteiros, 3) Monte da Saia, 4) Tongóbriga, 5) Armeá, 6) Galegos, 7) Pendia, 8) Coaña, 9) Fazouro, 10) Borneiro, 11) Coaña, 12) Pendia, 13) Chao Sanmartí, 14) Monte Ornedo. Made from González Ruibal 2006. 
plares asturianos, se asentaba más sobre proximidad espacial, mediando incluso el paso de una calle, que sobre iniciativa simultánea atestiguada. De hecho en Chao Samartín la deformidad del atrio parece que tiene que ver más bien con una ocurrencia posterior de adosar la sauna al flanco lateral-trasero de la casa de asamblea. La vinculación que ha establecido Ángel Villa (2011: 35) quedaría ahora validada de manera más fehaciente por la unidad de proyecto de los dos elementos que refleja Santa Marina. Pero este autor añade dos aspectos más de interés a considerar: el primero consiste en la constatación de que en los casos asturianos, la asociación entre cabaña de asamblea y sauna aparecen cerca de la puerta del castro en su tramo inicial, previo al ingreso en el caserío. Por lo que a Santa Marina respecta, no estamos en condiciones más que de reconocer que estaba a $96 \mathrm{~m}$ de la puerta este del recinto exterior, un tanto desviada, del sentido de la circulación y de la pendiente, pero a unos $90 \mathrm{~m}$ del acceso por otra posible puerta en el sur y en la línea de penetración directa al poblado. Es posible que hubiese otra puerta en el recinto interno. No se ha excavado por el momento en la zona donde cabría encontrar las cabañas, pero la pendiente del terreno invita a pensar que estarían en la zona más alta, con menor buzamiento de pendiente. De momento el emplazamiento indicaría equidistancia de las dos puertas. Sin embargo, las últimas tomas de datos cartográficas apuntan a la existencia de un recinto interno o una segunda línea de murallas del castro más constreñida que pudiese pertenecer, quizás, a una primera fase del castro con sus correspondientes puertas aún por localizar.

El otro aspecto digno de reseñar, aunque haya de quedar abierto, concierne a la propuesta de reconocer en las saunas, más bien santuarios. La hipótesis se realizaba en función de los aspectos rituales y las connotaciones religiosas que se pueden intuir en las saunas, pero podría quedar más refrendada aún por la naturaleza comunitaria y la envergadura del proyecto constructivo ejecutado en Santa Marina, así como por la amalgama entre funciones de relación y de sauna en un mismo complejo. Se podría pensar que este comportamiento es muy coherente con las funciones termales romanas, pero no hay duda alguna acerca de la cronología prerromana del edificio, que habría de datarse en el siglo II a. C y primera mitad del siglo I a.C. como etapa de vigencia más probable. Durante mucho tiempo se ha debatido no sólo lo que fueron las saunas del Noroeste, aunque ahora se ha convenido en reconocerlas como tales, sino también la cronología, viéndose como reinterpretaciones indígenas en época romana de las prácticas termales de los conquistadores. Ahora parece quedar fuera de duda que se les confiere una identidad prerromana (GONZÁLEZ RUIBAL,2006-2007: 571; TORRES, 2011: 318-320). Las dataciones más antiguas del grupo septentrional de saunas se han fijado para el siglo IV a. C. (VILLA, 2011).

Por último cabe consignar que, la sauna de Santa Marina constituye el primer ejemplar de sauna localizada en territorio cántabro. Fue propuesta una identificación en este sentido para una construcción rectangular de gran tamaño en la Espina del Gallego (PERALTA, 2003: 294), pero no ha llegado a verificarse. Lo mismo puede apuntarse para el castro de la Ulaña donde se han señalado dos grandes estructuras de planta rectangular con uno de sus lados rematados en círculo (una de 20,80 x 19,80 m y otra de $16 \times 7$ m), situadas cerca de las puertas de entrada, que si bien sus autores las han relacionado con el control defensivo o militar del acceso al asentamiento (CISNEROS y LÓPEZ, 2005:8182 y 153) o han postulado que puedan tener un "carácter colectivo" (MARÍN y CISNEROS, 2008: 153), o de santuario de entrada (CISNEROS et alii, 2011:70) bien podría apuntarse a que se trataran de estructuras similares a la aquí estudiada. Obviamente, el hallazgo entronca cada vez de manera más estrecha la cultura cántabra con la de los pueblos vecinos del Noroeste Hispánico, y lo hace en lo que entraña unas pautas sociales de conducta que enfatizan la dimensión socializadora de la vida comunitaria y la dimensión colectiva de las iniciativas urbanísticas, emprendidas en los poblados en forma de murallas, calles, aterrazamientos, saunas y, tal vez, santuarios. Queda abierta la lectura ritual del edificio por lo que atañe a la vertiente religiosa, pero no por lo que respecta a los ritos de socialización.

\section{BIBLIOGRAFÍA}

ALMAGRO GORBEA, M. y ÁLVAREZ SANCHÍS, J.R.

1993 La 'Sauna' de Ulaca. Saunas y baños iniciáticos en el mundo céltico. Cuadernos de arqueología de la Universidad de Navarra 1, 177-254.

ALMAGRO-GORBEA y M. Y MOLTÓ, L.

1992 Saunas en la Hispania prerromana. Espacio, tiempo y forma. Serie II, Historia Antigua 5, 67-102.

BARFIELD, L. Y HODDER, M.

1987 Burnt mounds as saunas, and the prehistory of bathing. Antiquity 61, 370-379.

BOHIGAS ROLDÁN, R.

1978 Yacimientos altomedievales de la antigua Cantabria. Altamira XLI, 17-48.

BOLADO DEL CASTILLO, R.; FERNÁNDEZ VEGA, P.A. y CALLEJO GÓMEZ, J.

2010 El recinto fortificado de El Pedrón (Cervatos), los campamentos de La Poza (Campoo de Enmedio, Cantabria) y el castro de Las Rabas (Cervatos, Cantabria): un nuevo escenario de las Guerras Cántabras. Kobie 29, 85-108.

\section{CARDOZO, M}

1931-32 A última descoberta arqueológica na Citânia de Briteiros e a interpretação da "Pedra Formosa. Revista de Guimarães $42(1-2), 7-25$

CISNEROS CUNCHILLOS, M.; GARCÍA SÁNCHEZ, J. y HERNÁNDEZ DOMÍNGUEZ, I.

2011 Los oppida del sector central de la Cordillera Cantábrica: síntesis y nuevas investigaciones. Palaeohispanica 11, 61-83. 
CISNEROS CUNCHILLOS, M. y LÓPEZ NORIEGA, P.

2005 El castro de La Ulaña (Humada, Burgos): la documentación arqueológica (1997-2001). Servicio de Publicaciones de la Universidad de Cantabria, Santander.

\section{ERICE LACABE, R.}

1995 Las fíbulas del Nordeste de la Península Ibérica: siglos I a.E. al / d.E. Institución Fernando el Católico, Zaragoza.

\section{FERNÁNDEZ VEGA, P. A. y BOLADO DEL CASTILLO, R.}

2010 Santa Marina (Monte Ornedo, Valdeolea). CASTROS Y CASTRA EN CANTABRIA. Fortificaciones desde los orígenes de la Edad del Hierro a las guerras con Roma. Catálogo, revisión y puesta al día. ACANTO Y Gobierno de Cantabria, Consejería de Cultura, Turismo y Deporte, 379-386.

GARCÍA GUINEA, M.A. y RINCÓN, R.

1970 El asentamiento cántabro de Celada Marlantes (Santander). Instituto de Prehistoria y Arqueología Sautuola. Institución Cultural de Cantabria. Diputación Provincial de Santander.

\section{GONZÁLEZ RUIBAL, A}

2006-07 Galaicos. Poder y comunidad en el Noroeste de la Península lbérica (1200 a. C. -50 d. C.). Brigantium 18 y 19 .

\section{GRABOWSKI, R}

2008 Fulachta Fiadh in County Cavan: A study of the use of archaeobotanical, geochemical and geophysical methods on burnt mounds in County Cavan, Ireland, Publications from the Environmental Archaeology Lab

HOVART, J.

2002 The Hoard of roman Republican Weapons from Grad near Šmihel. Arheološkivestnik 53, 117-192.

\section{IGLESIAS GIL, J.M.}

2002 Arqueología en luliobriga (Retortillo, Campoo de Enmedio, Cantabria). Monografías Arqueológicas de Cantabria. Consejería de Cultura, Turismo y Deportes del Gobierno de Cantabria y Servicio de Publicaciones de la Universidad de Cantabria.

JIMENO, A.; DE LA TORRE, J.I.; BERZOSA, R. y MARTíNEZ, J.P.

2004 La Necrópolis Celtibérica de Numancia. Arqueología en Castilla y León 12, Memorias.

\section{JORDÁ CERDÁ, F}

1983 Nueva guía del Castro de Coaña (Asturias). Guías de Arqueología Asturiana $n^{\circ}$ 1. Fundación Pública de Cuevas y Yacimientos Prehistóricos de Asturias. Oviedo.

\section{LORRIO ALVARADO, A.J}

1997 Los celtíberos, Universidad Complutense de Madrid, Universidad de Alicante, Murcia.

MARÍN ARROYO, A. B. y CISNEROS CUNCHILLOS, M.

2008 Consideraciones económicas sobre el oppidum de La Ulaña (Humada, Burgos): la explotación ganadera. Zephyrus: Revista de prehistoria y arqueología 62, 151-162.
MARINÉ ISIDRO, M.

2001 Fíbulas romanas en Hispania: la Meseta. Anejos de Archivo Español de Arqueología XXIV, CSIC, Madrid.

MENÉNDEZ GRANDA, A. y VILLA VALDÉS, A.

2009 Os Castros de Taramundi: reseña sobre el plan director e informe relativo al avance de las excavaciones arqueológicas. Excavaciones Arqueológicas en Asturias 20032006. Principado de Asturias. Oviedo, 455-463.

O'DRISCEOIL, D. A.

1988 Burnt mounds: cooking or bathing? Antiquity 62, 671-680.

PERALTA LABRADOR, E.

2003 Los Cántabros antes de Roma. Real Academia de la Historia

\section{RÍOS GONZALEZ, S}

2000 Consideraciones funcionales y tipológicas en torno a los baños castreños del No de la Península Ibérica. Gallaecia 19, 93-124.

SCHULTEN, A.

1942 Campamentos prerromanos de la región cantábrica. Archivo Español de Arqueología XV, n 46, 1-16.

SILVA, A. C. F.

1986 A Cultura castreja: no noroeste de Portugal. Câmara Municipal de Paços de Ferreira, Museu Arqueológico da Citânia de Sanfins.

SMITH, P.

1996 El depósito arqueológico de la cueva de Reyes (Matienzo). La Arqueología de los Cántabros. Actas de la Primera Reunión sobre la Edad del Hierro en Cantabria, 173-191.

\section{TAVARES DÍAS, L.}

1997 Tongobriga. Ministerio da Cultura, Instituto Portugues do Patrimonio Arquitectonico.

\section{TORRES MARTÍNEZ, J.F}

2011 El cantábrico en la Edad del Hierro. Real Academia de la Historia.

TORRES-MARTÍNEZ, J.F.; MARTÍNEZ VELASCO, A. Y LUIS MARIÑO, S. DE

2012 El oppidum de Monte Bernorio en la Cantabria histórica. Nueve siglos de historia, Kobie (Serie Paleoantropología) $n^{\circ} 31,137-156$

VILLA VALDÉS, A.

2000 Saunas castreñas en Asturias. I/ Coloquio Internacional sobre termas romanas en el Occidente del Imperio. Gijón, 97-114.

2011 Santuarios urbanos en la Protohistoria Cantábrica: algunas consideraciones sobre el significado y función de las saunas castreñas. Boletín de Letras del Real Instituto de Estudios Asturianos 177, 9-46. 
